\title{
Risk Indices Associated with the Insulin Resistance Syndrome, Cardiovascular Disease, and Possible Protection with Yoga: A Systematic Review
}

\author{
Kim E. Innes, MSPH, PhD, Cheryl Bourguignon, RN, PhD, and \\ Ann Gill Taylor, MS, EdD
}

Objective: To conduct a systematic review of published literature regarding the effects of yoga, a promising mind-body therapy, on specific anthropometric and physiologic indices of cardiovascular disease (CVD) risk and on related clinical endpoints.

Methods: We performed a literature search using 4 computerized English and Indian scientific databases. The search was restricted to original studies (1970 to 2004) evaluating the effects of yoga on CVD or indices of CVD risk associated with the insulin resistance syndrome (IRS). Randomized controlled trials (RCTs), nonrandomized controlled trials, uncontrolled (pre and post) clinical trials, and cross-sectional (observational) studies were included if they met specific criteria. Data were extracted regarding study design, setting, population size and characteristics, intervention type and duration, comparison group or condition, outcome assessment, data analysis and presentation, follow-up, and key results, and the quality of each study was evaluated according to specific predetermined criteria.

Results: We identified 70 eligible studies, including 1 observational study, 26 uncontrolled clinical trials, 21 nonrandomized controlled clinical trials, and 22 RCTs. Together, the reported results of these studies indicate beneficial changes overall in several IRS-related indices of CVD risk, including glucose tolerance and insulin sensitivity, lipid profiles, anthropometric characteristics, blood pressure, oxidative stress, coagulation profiles, sympathetic activation, and cardiovagal function, as well as improvement in several clinical endpoints.

Conclusions: Collectively, these studies suggest that yoga may reduce many IRS-related risk factors for CVD, may improve clinical outcomes, and may aid in the management of CVD and other IRS-related conditions. However, the methodologic and other limitations characterizing most of these studies preclude drawing firm conclusions. Additional high quality RCTs are needed to confirm and further elucidate the effects of standardized yoga programs on specific indices of CVD risk and related clinical endpoints. (J Am Board Fam Pract 2005;18:491-519.)

Cardiovascular disease (CVD) is the leading cause of death and disability in the United States and other industrialized nations, ${ }^{1-4}$ as well as in a growing number of developing countries. ${ }^{5-7}$ Leading to

Submitted 5 January 2005; revised 20 May 2005; accepted 31 May 2005.

From the Center for the Study of Complementary and Alternative Therapies, University of Virginia Health Systems, Charlottesville, VA

Funding: This work was made possible by grant S-T32AT00052 from the National Center for Complementary and Alternative Medicine (NCCAM). The contents of this paper are solely the responsibility of the authors and do not necessarily represent the official views of the NCCAM, or the National Institutes of Health.

Conflict of interest: none declared.

Corresponding author: Kim E. Innes, MSPH, PhD, Center for the Study of Complementary and Alternative Therapies, The Blake Center, Suite G113, PO Box 800905, University of Virginia Health Systems, Charlottesville, VA 22908-0905 (e-mail: kei6n@virginia.edu). premature morbidity and mortality, and to preventable losses of employment, earnings, and quality of life, CVD is clearly of pressing clinical and economic significance, underscoring the need for effective primary prevention efforts that target common, modifiable risk factors. Prominent among these are the physiologic and anthropometric risk factors associated with the insulin resistance syndrome (IRS), and the neuroendocrine and psychosocial alterations that may both predispose to and result from these IRS-related abnormalities.

The IRS, also referred to as syndrome $\mathrm{X}$ or the metabolic syndrome, is a cluster of metabolic and hemodynamic abnormalities that both collectively and independently predict the development of atherosclerosis and CVD. ${ }^{4,8-11}$ Core features of the IRS are insulin resistance, glucose intolerance, atherogenic dyslipidemia, high blood pressure, and 
visceral adiposity. ${ }^{8,10-12}$ Other abnormalities associated with the IRS include impaired fibrinolysis and increased coagulability, ${ }^{10,13-15}$ chronic inflammation, ${ }^{10-12,15}$ endothelial dysfunction, ${ }^{10,16,17}$ and oxidative stress. ${ }^{16}$ Insulin resistance (ie, resistance to insulin-stimulated glucose uptake) is thought to be the primary underlying defect and a cardinal feature linking the IRS with CVD. ${ }^{8,15,16,18-20}$

Increased sympathetic activity, enhanced cardiovascular reactivity, and reduced parasympathetic tone have also been strongly implicated in the pathogenesis of IRS ${ }^{10,21-29}$ and in the development and progression of atherosclerosis ${ }^{27,28,30,31}$ and cardiovascular disease. ${ }^{21,25,28-36}$ In addition, recent research offers compelling evidence that chronic psychological stress and negative affective states contribute significantly to the pathogenesis and progression of insulin resistance, ${ }^{37-41}$ glucose intolerance, ${ }^{38}$ hypertension, ${ }^{42-46}$ dyslipidemia, ${ }^{38,41,47}$ and other IRS-related conditions $\mathrm{s}^{28,37,48-55}$ and ultimately, increase risk for CVD morbidity and mortality. ${ }^{28,32,43,44,46,52,56-60}$

Not only can IRS-related conditions be exacerbated by lifestyle variables, such as smoking, lack of exercise, and poor diet, but these conditions can interact with one another in a destructive manner, ${ }^{61}$ likely accounting for their synergistic effect on CVD risk. ${ }^{9,62}$ Thus, a vicious cycle is initiated, which, as time goes on, becomes increasingly difficult to treat, highlighting the importance of early intervention. Given that IRS-related conditions affect a large percentage of the U.S. population, ${ }^{1,4,63}$ are now reaching epidemic proportions worldwide, ${ }^{1,64}$ and are powerful predictors of CVD morbidity and mortality, ${ }^{1,65}$ investigating potential cost-effective strategies for reducing IRS-related risk factors for CVD is clearly warranted.

In light of the strong influence of psychosocial factors on the development of both IRS and CVD, the role of sympathetic activation in the pathogenesis of insulin-resistant states, and the mutually exacerbating effects of these and other IRS-related risk factors, mind-body therapies may have considerable potential in the prevention and treatment of CVD. Of particular interest in this regard is yoga, an ancient mind-body discipline that has been widely used in India for the management of hypertension, diabetes, and related chronic insulin resistance conditions ${ }^{66,67-69}$ and may hold promise as a therapeutic intervention and health promotion measure for Western populations as well. Originat- ing in India over 4000 years ago, the practice of yoga has been rising steadily in western industrialized countries during recent decades. ${ }^{70-72}$ Of the 7 major branches of Hindu yoga, Hatha (or forceful) yoga, Raja (or classical) yoga, and Mantra yoga are perhaps the best known and most widely practiced forms. Mantra yoga, emphasizing the use of specific sounds or chants to achieve mental and spiritual transformation, has been popularized in the West by Maharishi Mahesh Yogi, the founder of Transcendental Meditation (TM). Both Hatha yoga and Raja yoga emphasize specific postures (asanas), including both active and relaxation poses, as well as breath control (pranayama), concentration (dharana), and meditation (dhyana). Hatha yoga, the branch of yoga most commonly practiced in the Western industrialized world and which itself includes many different styles (eg, Iyengar, Kundalini, Ashtanga, Integral, and Bikram yoga), also incorporates mantras or chants, cleansing exercises (kriyas), and specific hand gestures (mudras).

Yoga is an economical, noninvasive practice that has become increasingly popular in the United States as a means of potentially relieving stress, enhancing health, and improving fitness. ${ }^{70-73}$ With no appreciable side effects and multiple collateral lifestyle benefits, ${ }^{70,72,74,75}$ yoga seems safe, is simple to learn, and can be practiced even by elderly, ill, or disabled individuals. ${ }^{76}$ Requiring little in the way of equipment or professional personnel, yoga also seems easy and inexpensive to maintain, with some studies indicating excellent long-term adherence, ${ }^{77-79}$ even in Western populations. ${ }^{79}$ Most importantly, there is a growing body of research suggesting that practice of yoga may reduce IRSrelated risk factors for CVD, and may attenuate signs, reduce complications, and improve the prognosis of those with frank or underlying disease. $^{67-72,75,78,80}$

However, despite yoga's growing popularity and apparent promise as a safe and cost-effective intervention for populations with CVD or at risk for CVD, systematic reviews are lacking. In this article, we critically review the published scientific literature regarding the effects of yoga on IRS-related anthropometric and physiologic indices of CVD risk and on cardiovascular clinical outcomes, taking into account the major limitations and biases of these studies. We also briefly discuss mechanisms that may mediate the reported effects of yoga on CVD risk. 


\section{Methods}

There seems to be mounting evidence that yoga may indeed reduce IRS-related indices of CVD risk and aid in the management of CVD and other IRS-related chronic disorders. To examine this evidence systematically, we first conducted a thorough search of the published medical literature. The search was restricted to English language articles published after 1970 and available in U.S. libraries, and to original studies specifically evaluating the effects of yoga (alone or in combination with other interventions) on cardiovascular disease or IRS-related risk factors for cardiovascular disease. Specifically, original studies were included in the review if they reported outcome data and evaluated the effects of yoga and yoga-based interventions on measures of insulin resistance, lipid profiles, body weight or composition, blood pressure, oxidative stress, coagulation/fibrinolytic profiles, or on markers of sympathetic activation and cardiovagal function. We also included studies assessing the influence of yoga and yoga-based programs on relevant clinical endpoints, including medication use, CVD-related events and hospitalizations, and measures of CVD progression.

Because this review is focused on the influence of yoga on physiologic and anthropometric indices of CVD risk, those studies exclusively evaluating psychosocial risk factors for CVD were excluded. Case studies, abstracts from conference proceedings, and anecdotal reports were also eliminated, as were studies with intervention group sizes of less than 4 subjects. Studies evaluating only the effects of TM programs on CVD risk profiles and clinical outcomes were likewise excluded (for a comprehensive review of research on the use of this intervention in the treatment and prevention of coronary heart disease, see King et $\mathrm{al}^{81}$ ). Articles were identified using MEDLINE, PubMED, and PsycINFO, 3 commercially indexed, scientific databases. Because the majority of studies investigating the effects of yoga therapy have been conducted in the Indian subcontinent and these databases offer only incomplete capture of articles published in Indian medical journals, IndMED, a bibliographic database of over 75 major Indian biomedical journals, was also searched. Search words included yoga, yogic, relaxation, mind-body, and meditation. In addition, the citation sections of all identified articles were scanned to identify relevant pa- pers not indexed in PsycINFO, PubMED, MEDLINE, or IndMED.

Each eligible study (ie, each study identified that met our inclusion criteria) was classified into one of 5 design categories: randomized controlled trials, nonrandomized controlled trials, uncontrolled (pre and post) trials, cross-sectional (observational) studies, and studies assessing dynamic change in specific physiologic indices during 1 or 2 yoga sessions. In randomized controlled trials (RCT), a member of the investigative team randomly allocates a yoga or yoga-based program to one group (the experimental or yoga group) and no intervention, usual care, or another intervention to one or more other groups (controls). Both groups are then evaluated to determine change over time in specific indices of CVD risk. In nonrandomized controlled studies (controlled clinical trials [CCT]), a member of the investigative team allocates a yoga-based intervention to one group, and no intervention or another intervention to one or more other groups, but the allocation to a given treatment is not performed randomly. Both groups are again assessed to determine change over time in specific indices of CVD risk relative to baseline. In uncontrolled (pre and post) studies, all subjects participate in a yoga or yoga-based program, and change over time (baseline to post-intervention) in specific indices of CVD risk is evaluated. In cross-sectional (observational) studies, the investigator does not manipulate assignment of the intervention, but rather compares, at a single point in time, indices of risk between groups with varying experience in the practice of yoga. An additional study design category included studies that monitored temporary physiologic changes occurring during 1 or 2 yoga sessions; all but one of these studies ${ }^{82}$ included a comparison group and/or condition, although none were randomized.

We evaluated study quality using criteria based on those used in recent systematic reviews regarding the effects of another popular mind-body therapy. ${ }^{83,84}$ Criteria included (1) adequate sample size; (2) explicit eligibility criteria and/or adequate description of study population; (3) single, well-defined intervention; (4) appropriate control group(s) or comparison condition(s); (5) randomization of treatment allocation; (6) blinding of outcome assessment; (7) adequate accounting for confounders; (8) statistical methods well described and appropriate; (9) outcome measures well-defined and point 
estimates and measures of variability presented; (10) adequate follow-up/drop-out rate reported; and (11) conclusions supported by findings.

Outcomes evaluated were categorized into several different domains of CVD risk indices and clinical outcomes. For each domain, we summarized findings from relevant studies. Because of the heterogeneity of outcomes, study designs, settings, and interventions, we did not conduct a meta-analysis.

\section{Results and Discussion}

The literature search identified a total of 70 eligible studies on physiologic/anthropometric risk factors for cardiovascular disease and/or related clinical endpoints, including 1 cross-sectional study, 8 studies (7 controlled, 1 uncontrolled) examining changes occurring during 1 or 2 yoga sessions, 25 uncontrolled clinical trials, 15 nonrandomized controlled trials (including one study that also examined changes occurring during a single yoga session), and 22 RCTs (Table 1). The majority (63\%) of identified studies were published between 1990 and 2004, and most were small in size, with over $40 \%$ having study populations numbering under 25 subjects. Almost $70 \%$ of the studies were conducted in India; in contrast, less than $5 \%$ of studies identified were performed in the United States. Yoga-based interventions used in these studies ranged in duration from 2 days to 12 months, and included a single $(\mathrm{N}=18)$ or multiple components of yoga practice $(\mathrm{N}=35)$, and comprehensive yoga-based programs that included a special diet, lifestyle education, nonyogic exercise, stress management, or other interventions $(\mathrm{N}=17)$. The distribution of studies by study population and intervention (yoga alone versus multiple interventions) is given in Table 2. The majority of the studies identified for this review were conducted in healthy young to middle-aged adults $(50 \%)$ or in adults with or at risk for cardiovascular disorders $(30 \%)$. In contrast, few studies have evaluated the influence of yoga on CVD risk indices in populations with other chronic disorders $(\mathrm{N}=9)$, or in healthy children $(\mathrm{N}=3)$ or elderly adults $(\mathrm{N}=2)$ (Table 2). Table 3 lists the characteristics of eligible studies identified. The findings of these studies regarding the effects of yoga-based interventions on specific physiologic and anthropometric indices of CVD risk and relevant clinical endpoints are reviewed below.

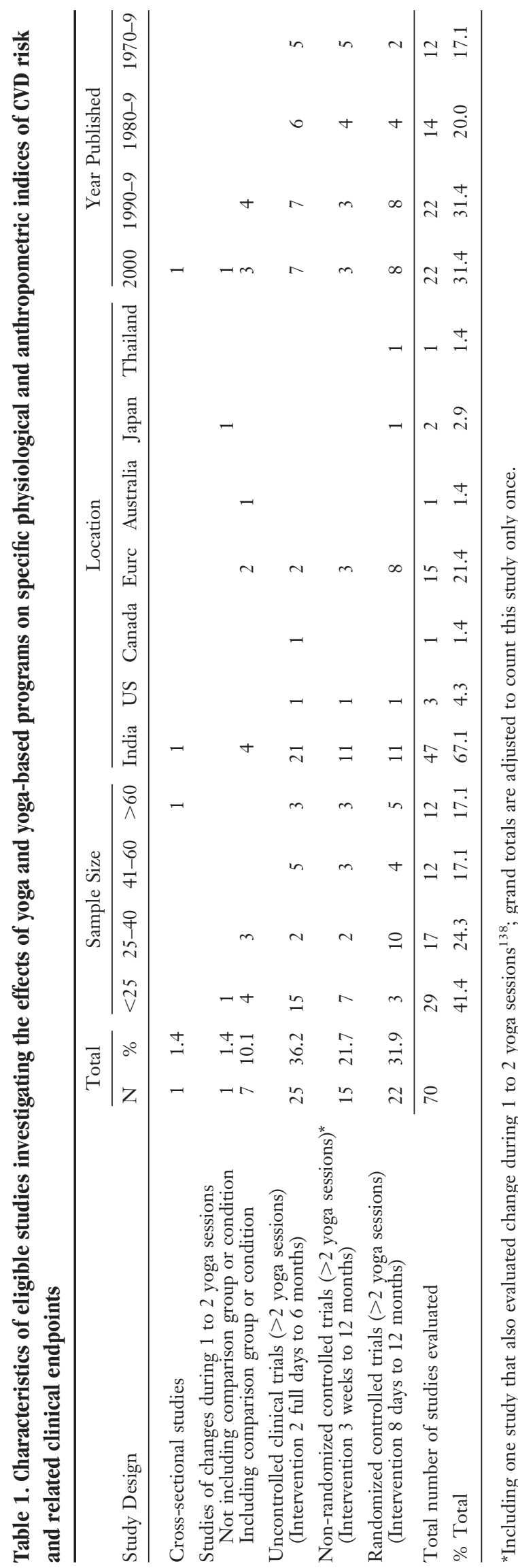

http://www.jabfp.org 


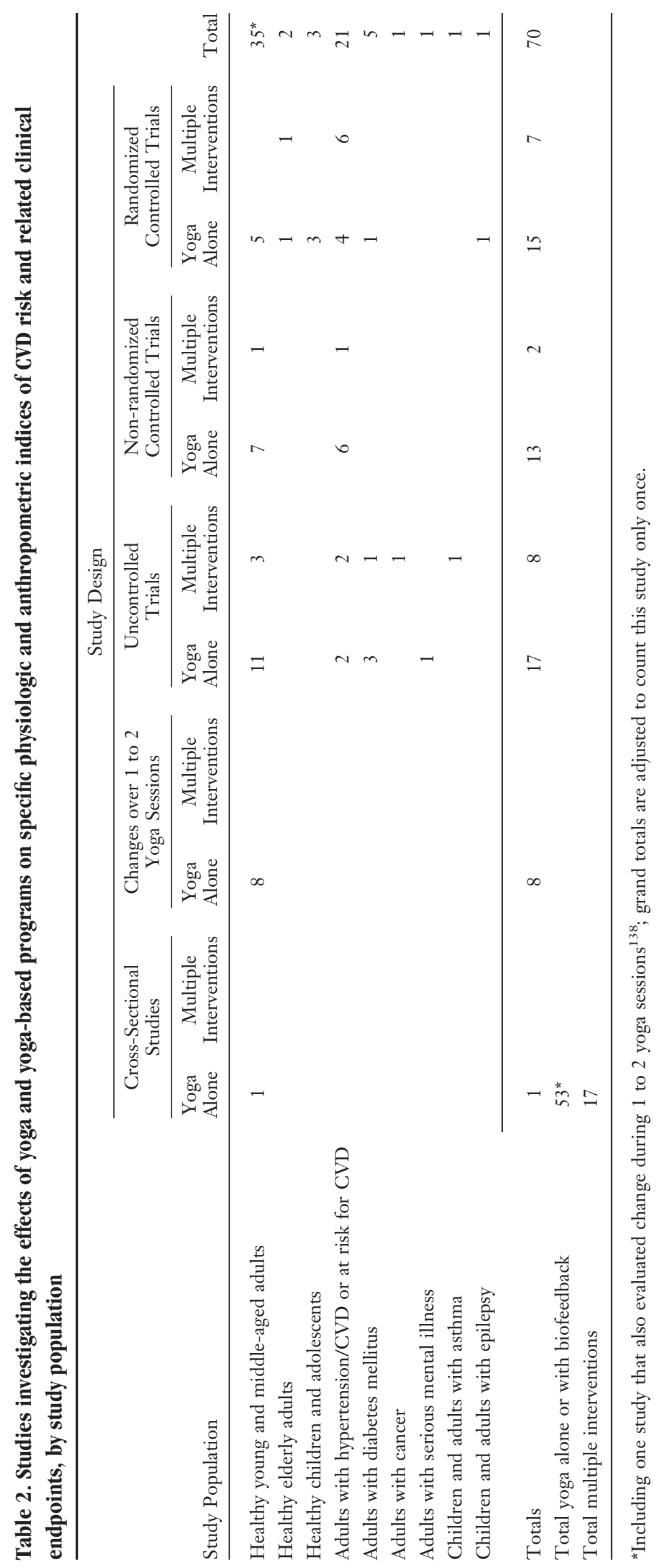




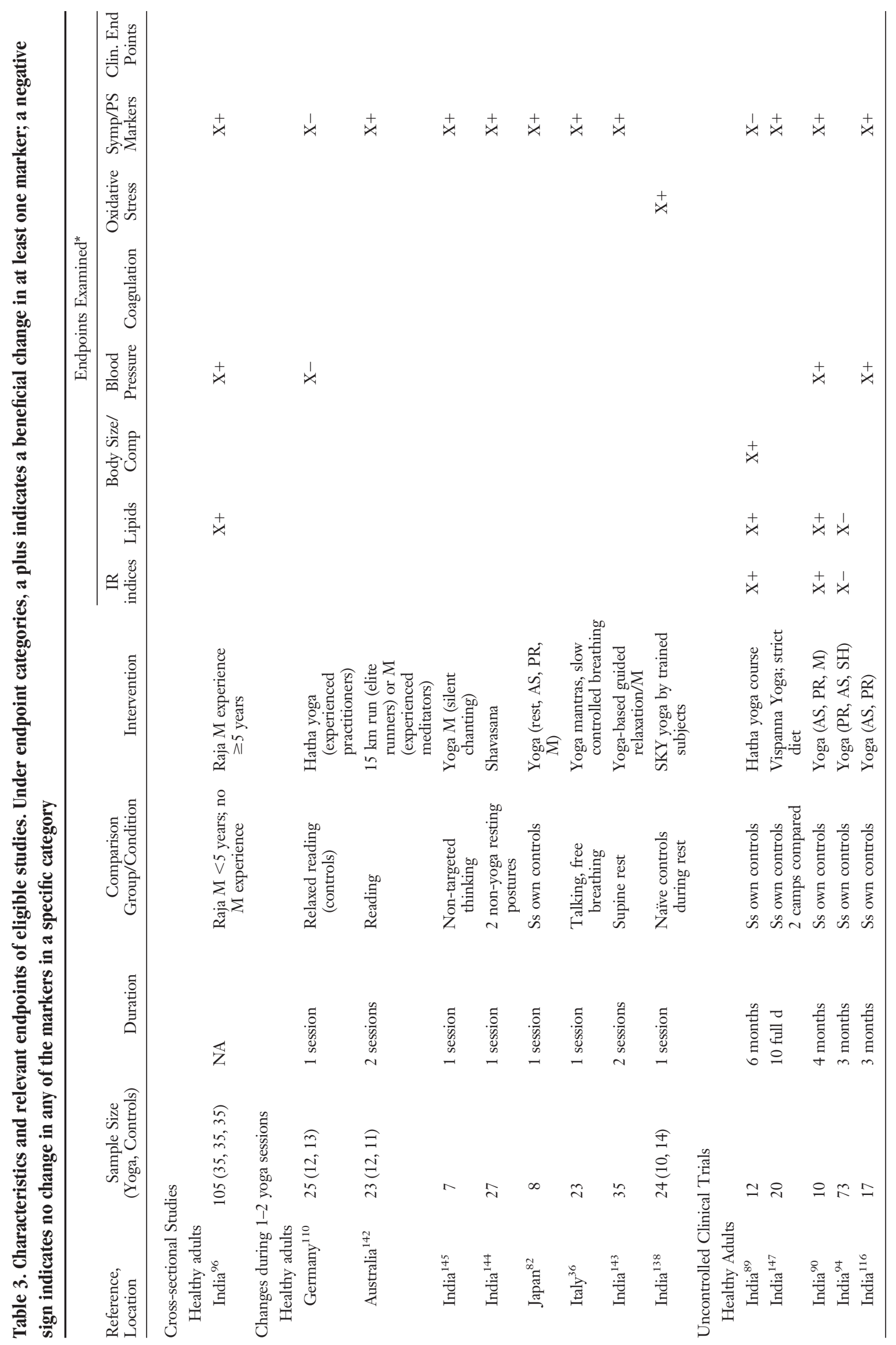




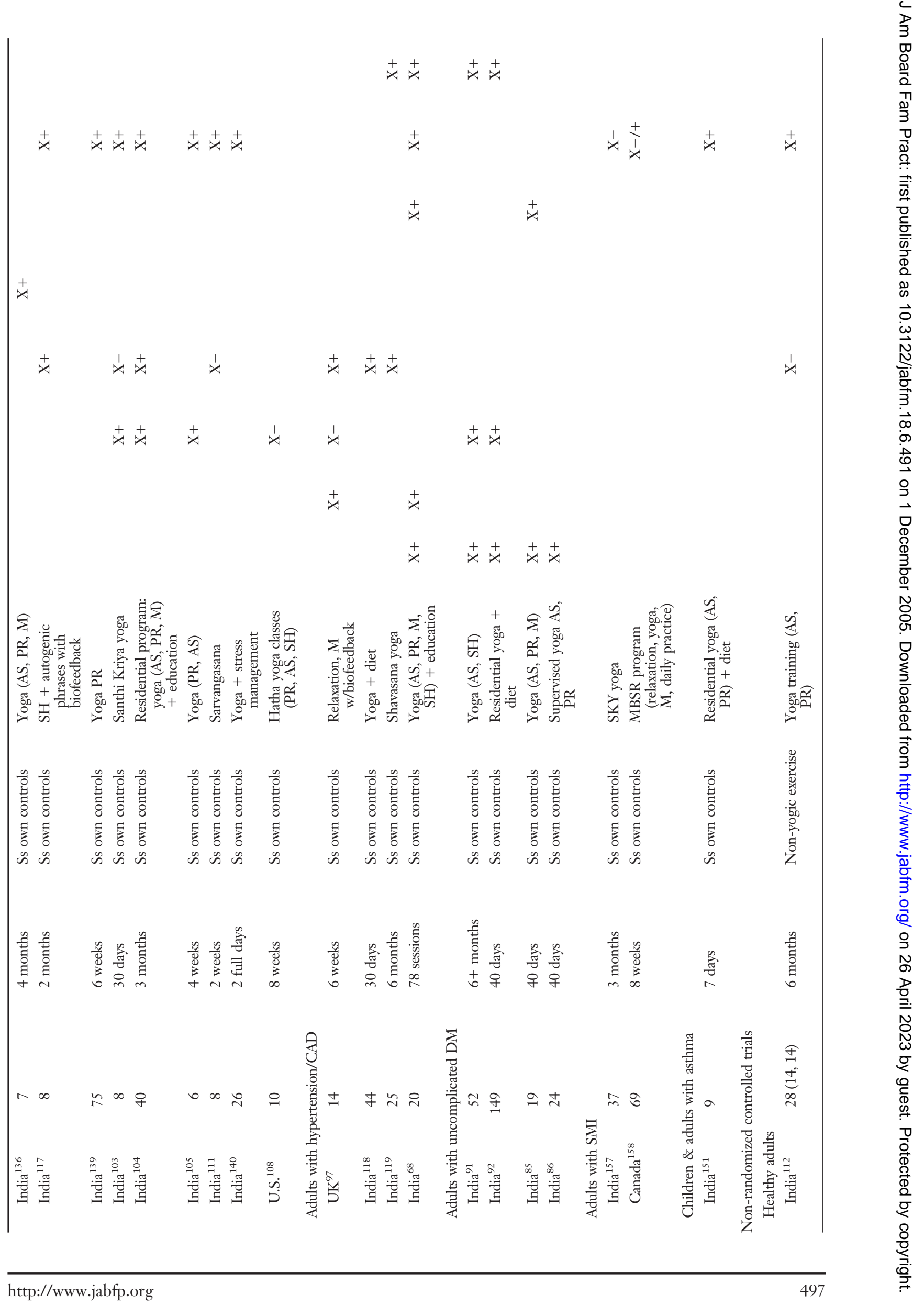




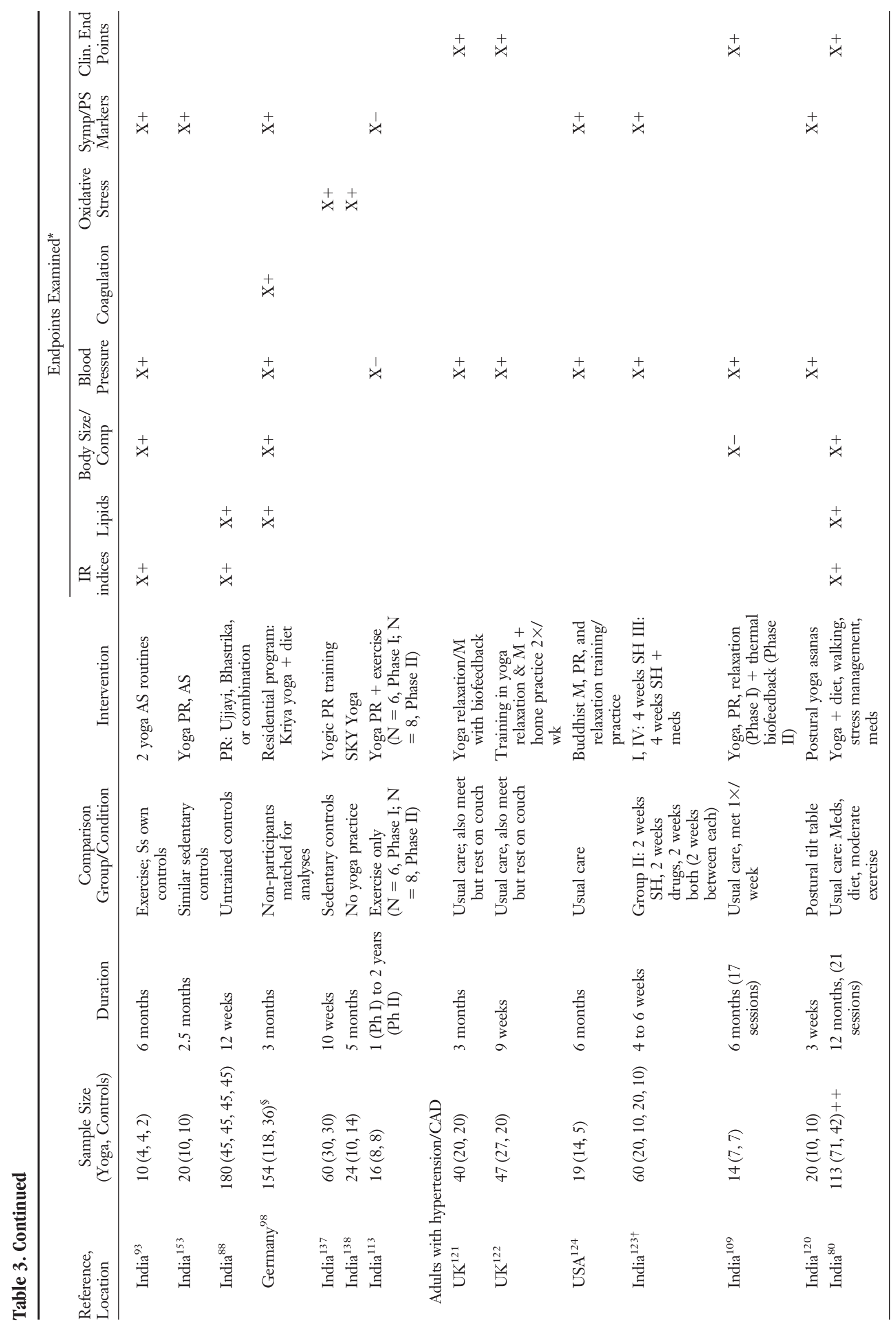




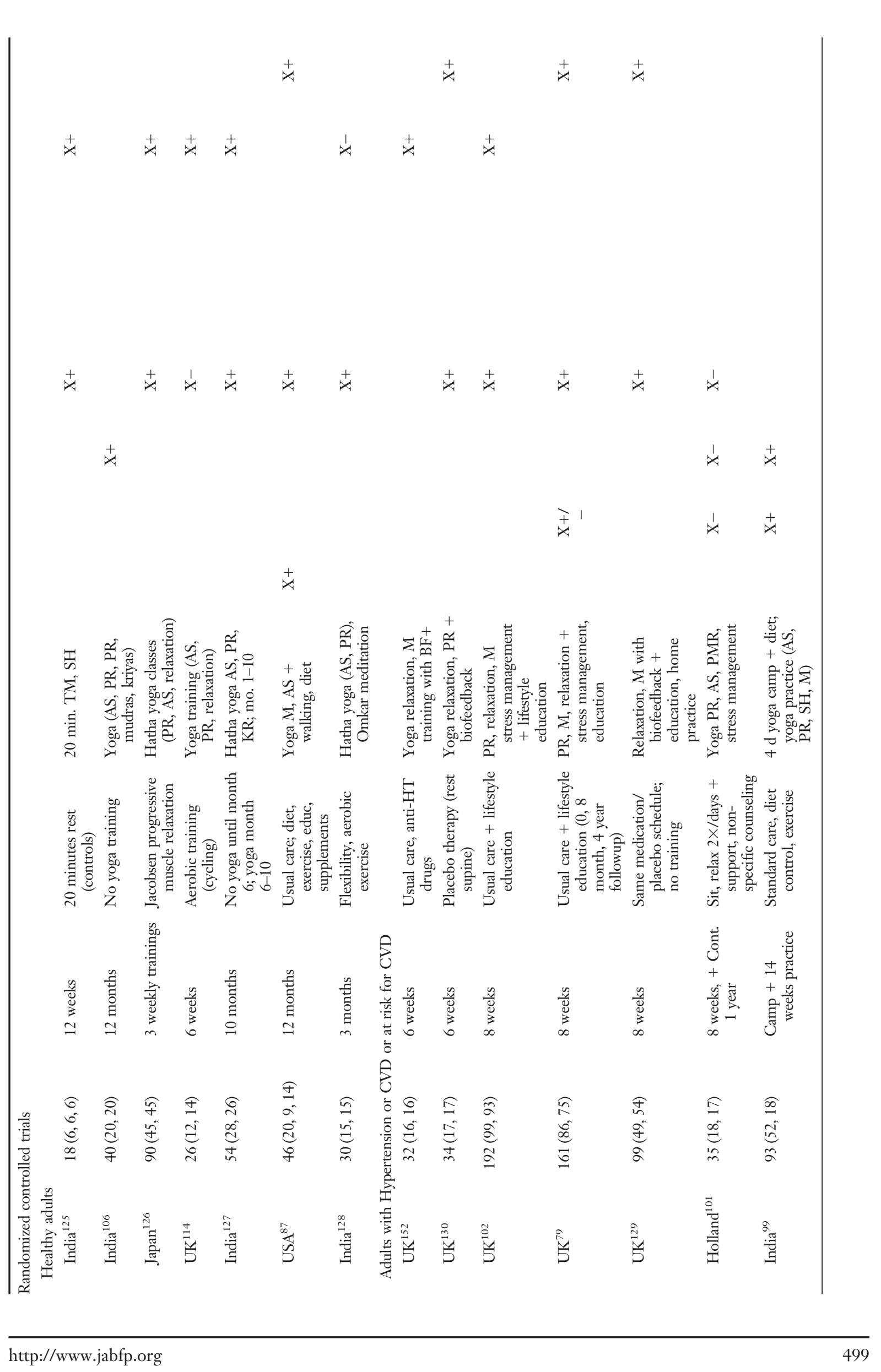

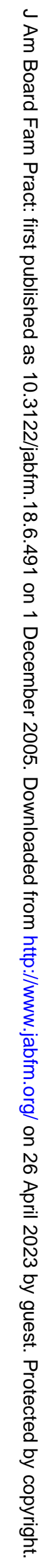




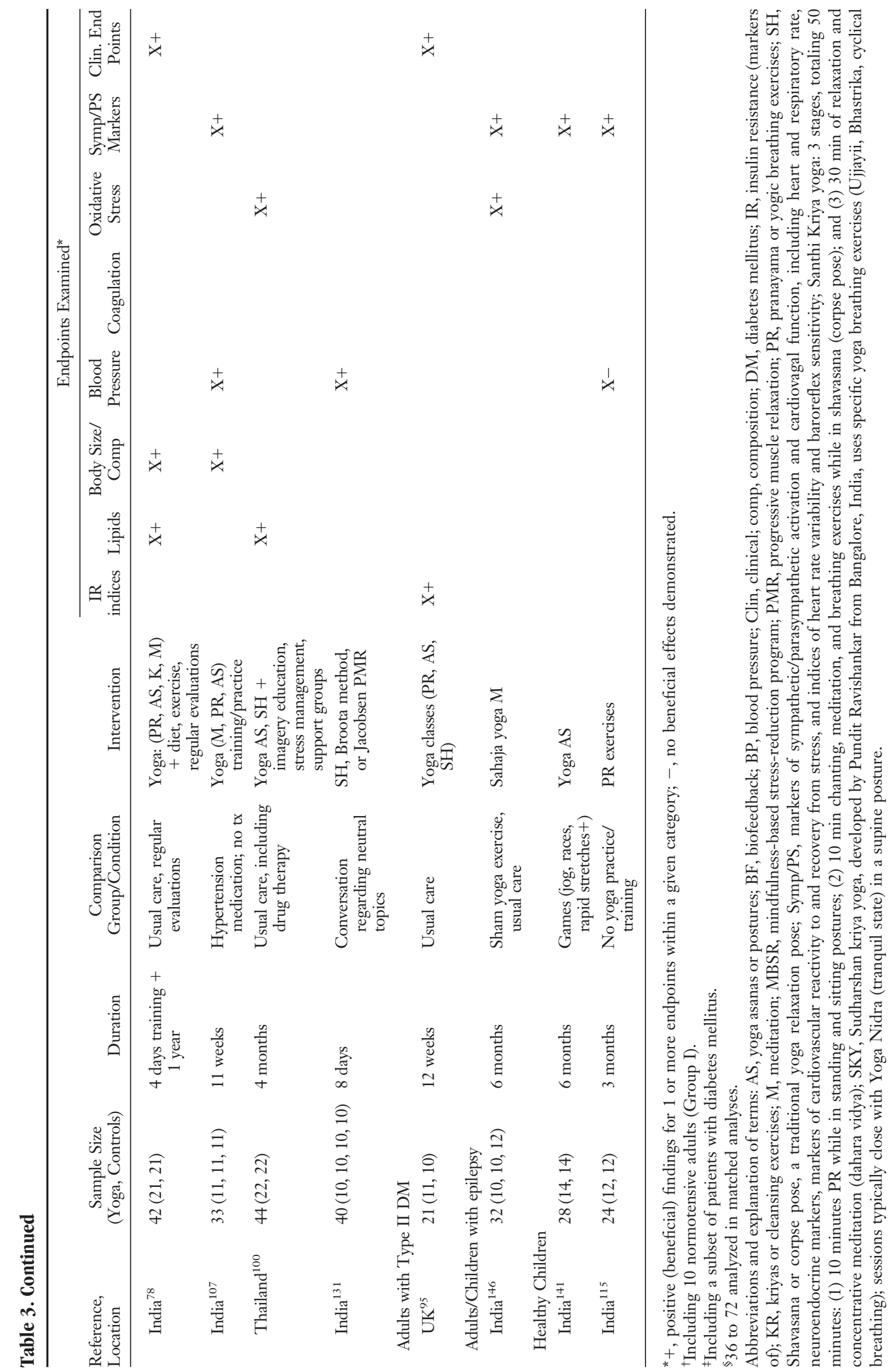


Observed Effects of Yoga on Core Indices of the IRS

Since the 1970s, at least 51 eligible, published studies from 7 countries have investigated the potential influence of yoga and yoga-based programs on one or more core indices of the IRS, including measures of insulin resistance, lipid profiles, body weight and composition, and blood pressure. Our literature search identified 13 eligible studies examining the influence of yoga-based interventions on markers of insulin resistance (including 8 uncontrolled clinical trials, 2 nonrandomized controlled trials, and 2 RCTs), 14 studies evaluating the effects of yoga on lipid profiles (including 1 crosssectional study, 5 uncontrolled clinical trials, 3 nonrandomized controlled trials, and 5 RCTs), and 18 studies assessing the influence of yoga on body weight or composition (including 9 uncontrolled trials, 3 nonrandomized controlled trials, and 6 RCTs. In addition, we identified 37 eligible studies evaluating the effects of yoga on blood pressure, including 1 cross-sectional study, 1 study examining changes during a single yoga session, 11 uncontrolled studies, 12 nonrandomized controlled studies, and 12 RCTs. Findings of these studies are summarized in Tables 4 and 6 and are discussed briefly below.

\section{Markers of Insulin Resistance}

Of the 13 studies evaluating the effects of yoga on markers of insulin resistance, most documented significant, postintervention improvement in one or more indices following the practice of yoga either alone or in combination with other therapies (Table 4). Interventions ranged in length from 40 days ${ }^{85,86}$ to 12 months, ${ }^{80,87}$ and all but one ${ }^{88}$ incorporated yoga asanas or postures. Seven of the 8 uncontrolled studies of healthy young adults, ${ }^{89,90}$ patients with type II diabetes mellitus (DM III) $85,86,91,92$ or hypertension $^{68}$ reported significant improvement postintervention in indices of insulin resistance relative to baseline values. Documented changes included reductions in fasting $68,80,85,86,88-90,92,93$ and postprandial glucose, ${ }^{85,86,89,91,92}$ and in fasting glycohemoglobin; ${ }^{85-87}$ in the one uncontrolled study yielding negative results, a trend toward reduced glucose was observed in male subjects despite low baseline levels $^{94}$ (Table 4). Likewise, nonrandomized controlled studies of healthy young adults ${ }^{88}$ and adults with coronary artery disease $(\mathrm{CAD})^{80}$ reported reductions in fasting glucose among subjects receiving a yoga-based intervention versus controls re- ceiving enhanced usual care ${ }^{80}$ or no active intervention ${ }^{88}$; descriptive findings of an additional small controlled study of healthy young men suggested similar improvement following a prescribed yoga program. ${ }^{93}$ In a small RCT of diabetic British adults, Monro et al demonstrated a decline in both fasting glucose and glycohemoglobin among participants attending structured yoga classes relative to usual care controls. ${ }^{95}$ Similarly, an RCT of American seniors demonstrated a substantial (19\%) reduction in fasting insulin among high-risk subjects completing a comprehensive integrative medicine program including yoga meditation and asanas, although small sample sizes precluded statistical comparison with controls. ${ }^{87}$ Overall, yoga practice was associated with a 5.4 to $33.4 \%$ reduction in fasting glucose, 24.5 to $27.0 \%$ reductions in postprandial glucose, and 13.3 to $27.3 \%$ reduction in glycohemoglobin, with the percentages varying by study population and design (Table 5).

Although the evidence for a beneficial effect of yoga on indices of insulin resistance is relatively consistent across studies, most studies (62\%) had no comparison groups ${ }^{68,85,86,89-92,94}$ and many had small sample sizes ${ }^{68,85,86,89,90,93,95}$ or reduced power due to stratified analyses. ${ }^{87,92,94}$ Others lacked detailed information on eligibility criteria or study population characteristics, ${ }^{80,85,86,88,89,93}$ and blinding of the outcome assessment was reported in only one study. ${ }^{87}$ The study sample selection process was unclear in several studies, ${ }^{86,89,90,93}$ and in others, potential selection bias, differential loss to follow-up ${ }^{80}$ and uncontrolled confounding factors such as demographic, anthropometric, and lifestyle characteristics $^{85,91-95}$ may have been important. The intervention was not well described ${ }^{88}$ or varied in duration ${ }^{91}$ in some studies; others included multiple interventions, ${ }^{68,80,87,92}$ rendering detection of the effect of a specific component difficult. Analytic methods were not well described in most studies $^{68,85,86,88,90-95}$; no statistical analysis was presented in some, ${ }^{68,89,91,93}$ and many had methodological problems, including lack of adequate point estimates for key outcome measures, ${ }^{68,89,91,93}$ failure to adjust for multiple comparisons, ${ }^{68,87,88,90,91,94}$ confusing data presentation, ${ }^{68}$ and other potential analytic problems. ${ }^{87,88}$ Among controlled studies, additional limitations included lack of randomization, ${ }^{80,88,93}$ failure to describe treatment allocation methods, ${ }^{80}$ and or absence of intergroup comparisons. ${ }^{93}$ 
Table 4. Summarized findings of studies (1970-2004) investigating the effects of yoga and yoga-based programs on insulin resistance, lipid profiles, and body size and composition, stratified by study design and intervention (yoga, including yoga-based meditation, alone vs. in combination with other interventions). Studies demonstrating beneficial effects are in bold type.

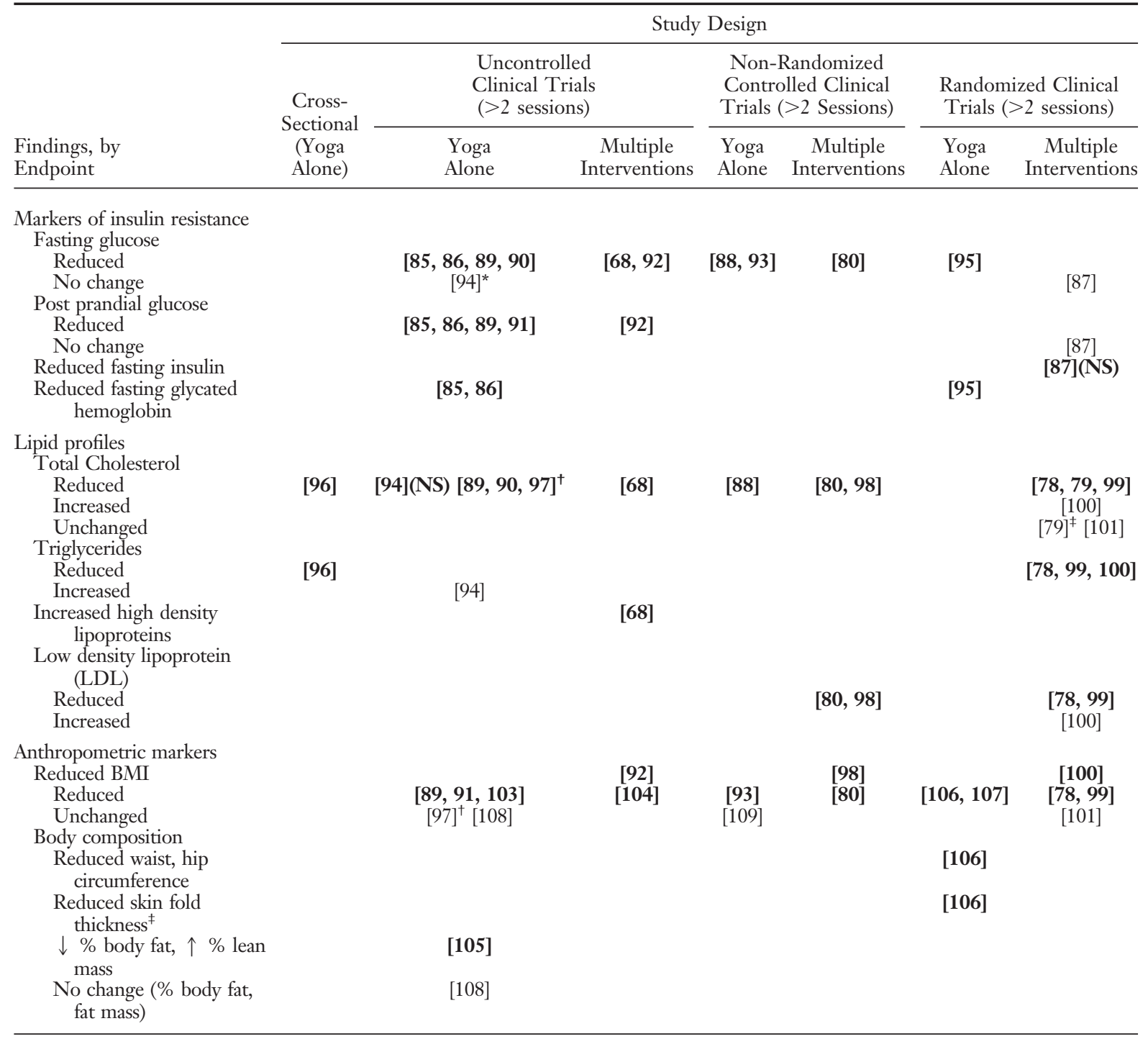

*Sexes analyzed separately; trend toward reduced fasting glucose in men $(\mathrm{N}=53,0.5<P<.1)$, despite low baseline fasting glucose levels $(x=64.4 \pm 6.2)$.

${ }^{\dagger}$ With biofeedback.

${ }^{\ddagger}$ In individuals at risk for CVD, cholesterol was lower at 0 and 8 months post-intervention, but not at 4 year follow-up

${ }^{\$}$ Triceps, subscapular, thigh, calf, etc, skin folds. ${ }^{106}$

\section{Lipid Profiles}

Of the 14 identified studies that examined the potential effects of yoga on blood lipid concentrations, most offered evidence suggesting that the practice of yoga and yoga-based programs may improve lipid profiles. In a cross-sectional study of healthy middle-aged men with similar lifestyle characteristics, Vyas and colleagues found those with both short-term and long-term experience in
Raja yoga meditation had reduced cholesterol and triglyceride levels relative to those with no yoga experience. ${ }^{96}$ Similarly, 4 of 5 uncontrolled studies ${ }^{68,89,90,97}$ and all 3 of the controlled, nonrandomized studies ${ }^{80,88,98}$ identified demonstrated significant positive changes in blood lipid levels following yoga-based interventions that ranged from 6 weeks ${ }^{97}$ to 12 months $^{80}$ in duration. These studies included investigations of both healthy adults and 


\begin{tabular}{|c|c|c|c|}
\hline $\begin{array}{l}\text { Findings, by Endpoint and } \\
\text { Population }\end{array}$ & $\begin{array}{l}\text { Uncontrolled } \\
\text { Clinical Trials } \\
(>2 \text { sessions })\end{array}$ & $\begin{array}{l}\text { Non-Randomized } \\
\text { Controlled Clinical } \\
\text { Trials ( }>2 \text { sessions) }\end{array}$ & $\begin{array}{l}\text { Randomized Clinical } \\
\text { Trials ( }>2 \text { sessions) }\end{array}$ \\
\hline \multicolumn{4}{|l|}{ Markers of insulin resistance } \\
\hline $\begin{array}{l}\text { Reduced fasting glucose } \\
\text { Healthy Adults } \\
\text { Adults with hypertension/CVD } \\
\text { Adults with type II diabetes } \\
\text { (DM II) }\end{array}$ & $\begin{array}{c}6.8 \%[90] \\
5.4-6.4 \%[68] \\
25.1-33.4 \%[85,86,92]\end{array}$ & $6.4-28.0 \%[88,93]$ & $6.9 \%[95]$ \\
\hline $\begin{array}{l}\text { Reduced postprandial glucose } \\
\text { Adults with type II diabetes } \\
\text { (DM II) }\end{array}$ & $24.5-27.0 \%[85,86,91,92]$ & & \\
\hline $\begin{array}{l}\text { Reduced fasting Insulin } \\
\text { Adults at risk for CVD }\end{array}$ & & & $19.2 \%[87]$ \\
\hline $\begin{array}{l}\text { Reduced fasting glycated } \\
\text { hemoglobin } \\
\text { Adults with type II diabetes } \\
\text { (DM II) }\end{array}$ & $13.3-27.3 \%[85,86]$ & & $15.5 \%[95]$ \\
\hline $\begin{array}{l}\text { Lipid profiles } \\
\text { Reduced total cholesterol } \\
\text { Healthy adults } \\
\text { Adults with hypertension/ } \\
\text { CVD + or DM II } \\
\text { Adults with other chronic } \\
\text { disorders }\end{array}$ & $\begin{array}{r}9.3 \%[90] \\
5.8-10.1 \%[68,97]\end{array}$ & $\begin{array}{r}8.0-8.2 \%[88][98] \\
25.2 \%[80]\end{array}$ & $14.8-21 \%[78,99]$ \\
\hline $\begin{array}{l}\text { Reduced triglycerides } \\
\text { Adults with hypertension/CVD+ } \\
\text { or DM II }\end{array}$ & & & $22.0-28.5 \%[78,99,100]$ \\
\hline $\begin{array}{l}\text { Reduced low density lipoprotein } \\
\text { (LDL) } \\
\text { Healthy adults } \\
\text { Adults with hypertension/CVD+ } \\
\text { or DM II }\end{array}$ & & $\begin{array}{l}12.8 \%[98] \\
26.0 \%[80]\end{array}$ & $19.1-23.3 \%[78,99]$ \\
\hline $\begin{array}{l}\text { Anthropometric markers } \\
\text { Reduced body weight } \\
\text { Healthy adults } \\
\text { Adults with } \\
\text { hypertension/CVD+ or } \\
\text { DM II }\end{array}$ & $1.5-9.1 \%[103,104]$ & & $\begin{array}{l}10.1 \%[106] \\
5.1-13.6 \%[78,99,107]\end{array}$ \\
\hline $\begin{array}{l}\text { Blood pressure } \\
\text { Reduced diastolic BP } \\
\text { Healthy adults } \\
\text { Adults with or at risk for CVD }\end{array}$ & $\begin{array}{l}7.7-8.8 \%[90,104,116] \\
8.5-16.7 \%[68,97,117-119]\end{array}$ & $\begin{array}{l}7.3-15.9 \%[9398] \\
12.7-17.5 \%[80,120-123]\end{array}$ & $\begin{array}{l}4.9-12.4 \%[125,127,128] \\
8.2-24.2 \%[79,87,107,129-131]\end{array}$ \\
\hline $\begin{array}{l}\text { Reduced systolic BP } \\
\text { Healthy adults } \\
\text { Adults with or at risk for CVD }\end{array}$ & $\begin{array}{l}2.6-7.3 \%[90,104,116] \\
7.1-17.0 \%[68,97,117-119]\end{array}$ & $\begin{array}{c}18 \%[98] \\
11.1-20.8 \%[80,120-123]\end{array}$ & $\begin{array}{l}6.8-9.3 \%[125,127,128] \\
4.4-21.3 \%[79,87,107,129-131]\end{array}$ \\
\hline $\begin{array}{l}\text { Reduced baseline respiratory rate } \\
\text { Healthy adults } \\
\text { Healthy children/adolescents } \\
\text { Adults with hypertension }\end{array}$ & $3.8-14.4 \%[103,104,116,139,140]$ & $60.3 \%[123]$ & $5.3 \%[141]$ \\
\hline $\begin{array}{l}\text { Reduced baseline heart rate } \\
\text { Healthy adults } \\
\text { Healthy children/adolescents } \\
\text { Adults with hypertension/CVD } \\
\text { Adults with other chronic } \\
\text { disorders }\end{array}$ & $4.3-38.8 \%[90,104,111,116]$ & $\begin{array}{l}4.3-8.2 \%[93,98] \\
9.5-23.5 \%[120,123]\end{array}$ & $\begin{array}{c}5.0-11.6 \%[114,115,125-127] \\
17.0-30.2 \%[115,141] \\
8.4 \%[107]\end{array}$ \\
\hline
\end{tabular}

*Including studies reporting improvement in these indices; studies not reporting point estimates or presenting sufficient data to allow reliable calculation of point estimates were excluded; weighted averages were calculated for studies presenting only stratified data (e.g., by sex).

CVD, cardiovascular disease.

patients with hypertension or CAD (Table 3). Observed changes included reductions in cholesterol and low density lipoprotein (LDL), ${ }^{68,80,88-90,97,98}$ and increases in high density lipoprotein (HDL) levels $^{68}$ relative to baseline levels ${ }^{68,89,90,97}$ and/or control values. ${ }^{80,88,98}$ In agreement with these find- 
ings, several RCTs investigating the effects of yoga in combination with diet, ${ }^{78,80,99}$ education, ${ }^{79}$ stress management, ${ }^{79,80,100}$ and other therapies ${ }^{78,80,100}$ have likewise demonstrated significant improvement in lipid profiles relative to controls receiving enhanced usual care, exercise, and/or dietary interventions (Tables 3 and 4). Of the 5 RCTs identified, all adults with hypertension, ${ }^{101} \mathrm{CVD},{ }^{78,100}$ or risk factors for $\mathrm{CVD},{ }^{79,99} 3$ documented improvement in all indices of dyslipidemia examined, ${ }^{78,79,99}$ and one reported significantly greater reductions in triglycerides, but not in cholesterol or LDL. ${ }^{100}$ In a follow-up of an earlier British study, ${ }^{102}$ Patel and colleagues reported maintenance of lipid profile changes at 8 months postintervention, but no differences between the yoga relaxation/meditation and the control groups at 4 years. ${ }^{79}$ Only one RCT, a study of 35 hypertensive Dutch adults (18 intervention group, 17 controls), reported no differences between the intervention and control groups. ${ }^{101}$ Of those studies demonstrating positive effects, yoga practice was associated with a $5.8 \%$ to $25.2 \%$ decrease in total cholesterol, $22.0 \%$ to $28.5 \%$ reduction in triglycerides, and a $12.8 \%$ to $26.0 \%$ reduction in LDL, with the observed magnitude of the effects differing by study population and design (Table 5).

Again, the vast majority of both uncontrolled and controlled studies suggest that the practice of yoga may have a positive influence on lipid profiles. However, many of the studies evaluated have methodological or other limitations that hinder interpretation of findings, including absence of comparison groups or conditions, ${ }^{68,89,90,94,97}$ low power because of small sample sizes ${ }^{68,89,90,97}$ or other factors, ${ }^{94,101}$ lack of evidence for blinded outcome assessment, ${ }^{68,79,80,88-90,94,96-101}$ possible uncontrolled confounding factors, ${ }^{94,96-101}$ potential selection bias, ${ }^{96,98,100}$ loss to follow-up, ${ }^{80}$ lack of randomization $^{88,98}$ or information on the randomization process, ${ }^{78,79,99,100}$ unclear statistical analyses, ${ }^{68,79,88,90,94,97,98}$ and multiple ${ }^{68,78-80,99-101}$ or poorly defined interventions. ${ }^{88,97}$ Other methodological issues include lack of adequate point estimates, ${ }^{68,88,89,98}$ intergroup comparisons, ${ }^{100}$ or adjustment for multiple comparisons, ${ }^{68,88,90,94,98,100}$ possible floor effects, ${ }^{94}$ and inadequate description of study populations ${ }^{80,88,89,99,101}$ and of sampling or treatment allocation process. ${ }^{80,89,90}$

\section{Body Weight and Composition}

Between 1970 and 2004, 18 clinical trials in 6 countries examined the effects of yoga on anthropometric indices of CVD risk (Table 4). Six of the 8 uncontrolled clinical trials and 3 of the 4 nonrandomized controlled studies identified reported improvement in body weight $t^{80,89,91-93,98,103,104}$ or composition $^{105}$ after yoga-based interventions ranging from 4 weeks ${ }^{103,105}$ to 12 months. ${ }^{80}$ Likewise, 5 of 6 randomized controlled trials, including 4 conducted in India ${ }^{78,99,106,107}$ and one completed in Thailand, ${ }^{100}$ demonstrated improvement in body weight and/or composition relative to usual care ${ }^{78,100,107}$ diet and exercise, ${ }^{99}$ and no intervention controls. ${ }^{106}$ Studies reporting improvement in anthropometric characteristics included investigations of healthy populations, ${ }^{89,93,98,103-106}$ as well as those with hypertension ${ }^{107}$ and/or other CVD risk factors, ${ }^{99} \mathrm{CAD},{ }^{78,80,100}$ or diabetes. ${ }^{91,92}$ Of those studies reporting improvement in anthropometric indices, yoga practice was associated with a $1.5 \%$ to $13.6 \%$ reduction in body weight (Table 5). All studies reporting a positive change in these indices used interventions incorporating active yoga asanas, whereas only one ${ }^{108}$ of those showing no effect, an uncontrolled 8-week study of 10 U.S. university students, included active postures as a central component in the intervention.

Limitations of these studies include lack of control groups, ${ }^{89,91,92,97,103-105,108}$ reduced power because of a low number of study subjects ${ }^{89,93,97,103,105,108,109}$ or other factors, ${ }^{92,101}$ possible selection bias ${ }^{98,105,108}$ or influence of uncontrolled confounding 91-93,97-101,103,107,109 lack of appropriate statistical analyses or presentation, ${ }^{89,91,93,98}$ inadequate description of analytic methods, ${ }^{91-93,97,98,105,106}$ study population, ${ }^{*}$ treatment allocation, ${ }^{80}$ or sample selection process, ${ }^{89,93,106}$ loss to follow-up, ${ }^{80,105,108}$ multiple comparisons, ${ }^{\dagger}$ failure to compare control and intervention groups, ${ }^{93,100,109}$ lack of randomization ${ }^{93,98,109}$ or description of randomization methods, ${ }^{78,99,100,106,107}$ and multiple interventions. ${ }^{78,80,92,99-101,104}$ In addition, only one study ${ }^{78}$ reported blinded outcome assessment.

*See References 80, 89, 91, 93, 99, 101, 104, 106, 107, 109

${ }^{\dagger}$ See References 91, 98, 100, 104-106, 108, 109 


\section{Blood Pressure}

Of the core indices of IRS, blood pressure is the endpoint that has been most extensively studied with respect to the influence of yoga-based interventions. Our search identified 37 studies from 6 countries, including 24 controlled studies. Over $75 \%$ of these studies report improvement in blood pressure with yoga or yoga-based interventions (Table 6). In a cross-sectional study of healthy mid-life men with similar lifestyle characteristics, Vyas and colleagues found those with both shortterm and long-term experience in Raja yoga meditation had reduced diastolic blood pressure compared with those who were naïve to meditation. ${ }^{96}$ Of the 36 remaining studies evaluating change in baseline blood pressure with yoga and yoga-based programs, only 8 studies (22\%) found no evidence of improvement, including a small German study of changes in healthy young female practitioners during a single yoga session, ${ }^{110} 2(20 \%)$ of the 10 uncontrolled studies, ${ }^{103,111} 2$ (17\%) of the 12 nonrandomized controlled trials, ${ }^{112,113}$ and 3 (25\%) of the 13 RCTs. ${ }^{101,114,115}$ Of the 4 uncontrolled and nonrandomized controlled trials with negative findings, all were small studies of healthy young Indian men that demonstrated no change in blood pressure, but an improvement in heart rate ${ }^{111,112}$ and/or other indices of cardiovascular function ${ }^{103,111,113}$; 2 of the 4 studies included active yoga asanas. ${ }^{103,112}$ RCTs yielding negative results included a 6-week study of healthy British elderly, and a 3-month study of healthy Indian boys that demonstrated no impact on blood pressure, but a significant reduction in heart rate and increase in heart rate variability (see below) in participants completing a yoga program compared with those receiving an aerobic exercise program ${ }^{114}$ or no intervention. ${ }^{15}$ In a third study of hypertensive Dutch elderly, the authors found a multimodal program that included training in yoga relaxation techniques to have no effect on 24-hour ambulatory blood pressure. ${ }^{101}$

In contrast, 28 eligible intervention studies published between 1970 and 2004 reported a beneficial effect of yoga and yoga-based programs on blood pressure change (Table 6). These include 8 uncontrolled studies of healthy ${ }^{90,104,116,117}$ and hypertensive adults, ${ }^{97,118,119}$ all but one of which ${ }^{97}$ were conducted in India. Most of these studies were small, with only $3^{104,118,119}$ including 25 participants or more. Among nonrandomized controlled trials, 9 studies of healthy adults ${ }^{93,98}$ and adults with hypertension ${ }^{109,120-124}$ and/or $\mathrm{CAD}^{80}$ have demonstrated significant reductions in blood pressure among participants who completed a yoga-based intervention relative to controls receiving an exercise, ${ }^{125}$ enhanced usual care ${ }^{109,121-123}$ or no intervention. ${ }^{98,125}$ Likewise, 11 RCTs of healthy adults $^{125-128}$ and patients with hypertension or other CVD risk factors ${ }^{79,87,102,107,129-131}$ have demonstrated significant blood pressure declines among subjects receiving a yoga-based intervention versus controls receiving usual care, ${ }^{107,129}$ enhanced usual care with diet and exercise,${ }^{87,128}$ social contact, ${ }^{131}$ placebo therapy, ${ }^{129,130}$ or no active intervention. ${ }^{107,127}$ In a study of 95 female Japanese university students, Cusumano and colleagues demonstrated comparable, significant reductions over time in blood pressure among women receiving 3 weekly training sessions in either Hatha yoga or progressive muscle relaxation. ${ }^{126}$ Overall, these studies demonstrated a $4.9 \%$ to $24.2 \%$ decline in diastolic blood pressure and a $2.6 \%$ to $21.3 \%$ decline in systolic blood pressure with yoga, with the magnitude of change varying with the study design and sample population (Table 5).

Yoga-based programs used in the 28 studies reporting positive findings ranged in duration from 30 days $^{118}$ to 6 months ${ }^{119}$ in the uncontrolled studies, from 3 weeks ${ }^{120}$ to 6 months ${ }^{93,109,124}$ in the controlled nonrandomized studies, and from 8 days ${ }^{131}$ to 12 months $^{87}$ in the RCTs. Interventions associated with blood pressure improvement included yoga routines both alone $(\mathrm{N}=20)$ and in combination with other therapies $(\mathrm{N}=8){ }^{\ddagger}$ Of those studies using yoga alone, 10 incorporated active yoga asanas $\$$ and 10 used relaxation postures alone 117,119,123,131 or in combination with meditation. ${ }^{97,121,122,124,125,130}$

Collectively, the findings of both controlled and uncontrolled studies suggest that even the relatively short-term practice of yoga or yoga-based programs may reduce blood pressure. However, because of potential biases and limitations characterizing most of these studies, caution is nonetheless warranted in drawing firm conclusions. For example, interpreting the positive findings of many of

\footnotetext{
${ }^{\ddagger}$ See References 68, 79, 87, 98, 102, 104, 118, 129.

${ }^{\$}$ See References 90, 93, 104, 107, 109, 116, 120, 126-128.
} 


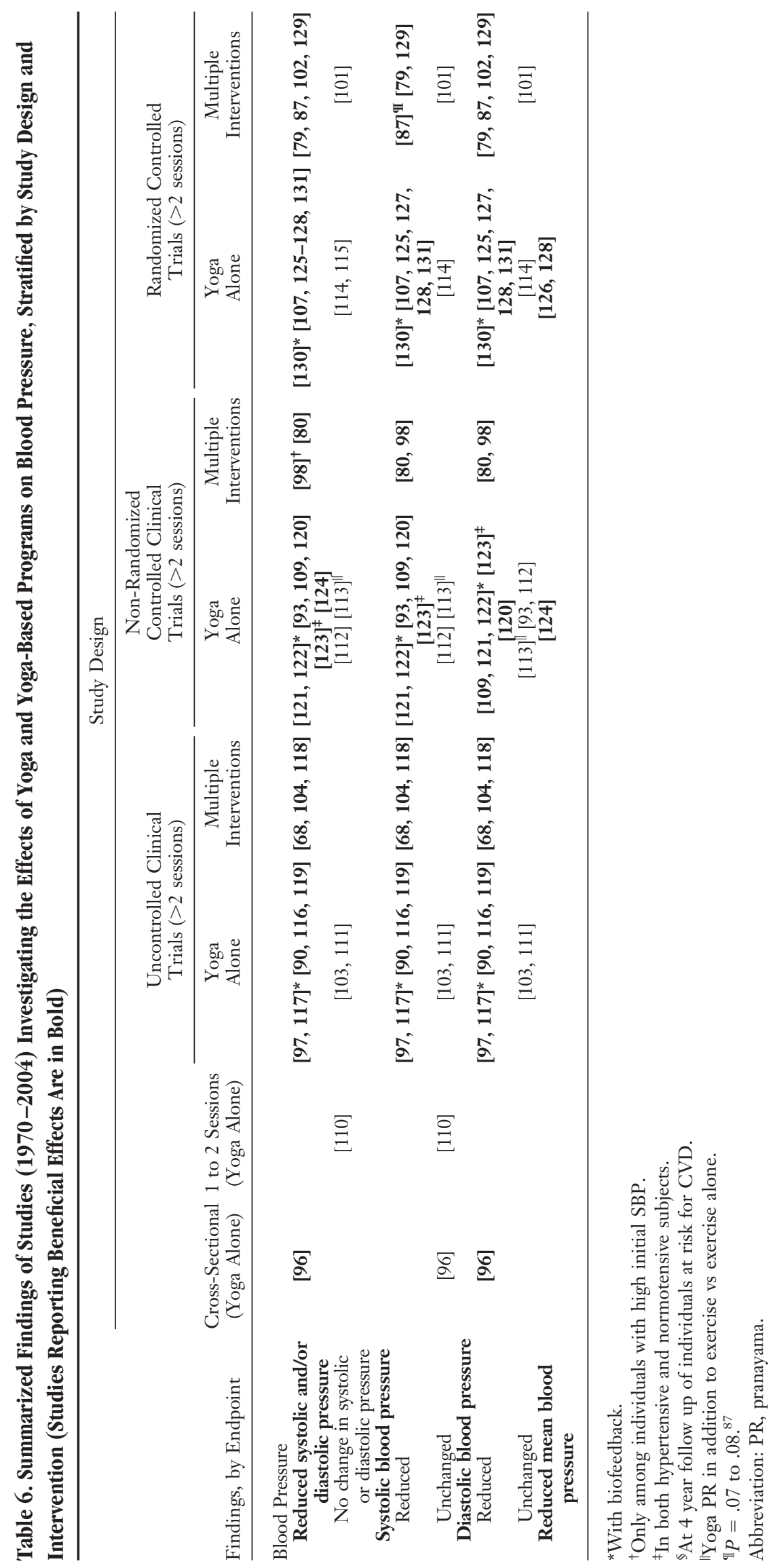


these studies is hindered by absence of comparison groups, ${ }^{68,90,97,104,116-119}$ small sample sizes," reduced power due to stratified analyses ${ }^{87,118,127}$ or other factors, ${ }^{101,131}$ possible selection bias or confounding by lifestyle or other factors, ${ }^{\text {II }}$ absence of detailed information regarding the study population, ${ }^{* *}$ the intervention, ${ }^{97,121,124}$ statistical $^{\dagger \dagger}$ or randomization methods, treatment allocation, ${ }^{80,124}$ or subject selection process, ${ }^{90,93,117,119,123}$ potential uncontrolled variation in exposure to the intervention, ${ }^{96,118}$ or loss to follow-up. ${ }^{80,116,121,122}$ Few studies reported blinding of outcome assessment, ${ }^{87,128-130}$ and several studies used yoga in

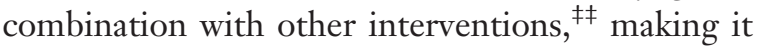
difficult to detect an effect specific to yoga. Other methodologic limitations are lack of randomization $^{93,98,109,121-125}$ and inadequacies in statistical analyses or presentation, including lack of appropriate point estimates, ${ }^{68,93,98}$ adjustment for multiple comparisons ${ }^{\$ \$}$ and appropriate comparisons between $^{93,109,120,122,123,128,131}$ or within ${ }^{68,93,117,123}$ groups.

\section{Observed Effects of Yoga on Indices of Coagulopathy and Oxidative Stress}

Procoagulant changes and damage caused by oxidative stress are thought to mediate many of the atherosclerotic and thrombotic changes that are associated with IRS ${ }^{13,14,132-134}$ and to play a pivotal role in the development and progression of CVD $^{13,132-134}$ and diabetes. ${ }^{135}$ Although few published studies have examined the possible effects of yoga and yoga-based interventions on coagulation profiles or oxidative stress, findings of these studies, summarized in Table 7, suggest that yoga may be instrumental in improving these important indices of CVD risk. An uncontrolled Indian study of 7 healthy young men naive to yoga demonstrated a significant decline in fibrinogen and a significant increase in fibrinolytic activity following a 4-month

"See References 68, 90, 93, 97, 109, 116, 117, 119, 120, 124, 125

${ }^{\mathbb{I}}$ See References 93, 96-98, 101, 107, 109, 118-120, 124127.

${ }^{* *}$ See References 80, 93, 101, 104, 107, 109, 117, 119, $121,123,130,131$

${ }^{+}$See Refernces 68, 79, 90, 93, 97, 98, 102, 116-119, 121-123, 125, 131. 130 .

${ }^{\ddagger \neq}$ See References $68,79,80,87,101,102,104,118,129$,

${ }^{\S}$ See References 68, 87, 90, 98, 104, 109, 116, 123, 125, 127. yoga training course, in addition to a pronounced, although nonsignificant increase in platelet aggregation and activated partial thromboplatin time, and a rise in blood platelets. ${ }^{136}$ Likewise, in a nonrandomized controlled study of healthy German adults, Schmidt et al documented a significant fall in fibrinogen among participants completing a 3 -month residential Kriya yoga program relative to community controls matched on age, gender, and baseline fibrinogen levels $(\mathrm{N}=76$ subjects, including 38 controls). ${ }^{98}$ Although limited, these data suggest that yoga may foster beneficial changes in the coagulation and fibrinolytic systems, at least in healthy adults.

We identified 5 eligible studies investigating the influence of yoga on measures of oxidative stress, including 2 uncontrolled clinical trials, 2 nonrandomized controlled clinical trials, and one RCT (Table 7). All but one of these studies ${ }^{100}$ were conducted in India, and all provide evidence that yoga may reduce oxidative stress in both healthy populations and those with chronic IRS-related disorders. In uncontrolled studies of Indian adults with uncomplicated diabetes mellitus, ${ }^{85}$ or hypertension, ${ }^{68}$ investigators demonstrated significant reductions in malonyldialdehyde (MDA), a circulating product of lipid peroxidation, following a 40 -day yoga training course ${ }^{85}$ and a 12 -week yoga lifestyle intervention, ${ }^{68}$ respectively. In agreement with these findings, nonrandomized controlled trials have shown significant reductions in $\mathrm{MDA}^{137}$ and other markers of oxidative stress ${ }^{137,138}$ in healthy young men completing a 10 -week ${ }^{137}$ to 5 -month ${ }^{138}$ yoga training program relative to matched untrained controls. Observed changes in other oxidative stress indices include increases in antioxidants ${ }^{138}$ and antioxidative enzymes, ${ }^{138}$ and reductions in free radicals. ${ }^{137}$ Offering further support for a direct effect of yoga on oxidative stress, Sharma et al documented significant improvement in several of these indices among trained participants during a single yoga session when compared with controls during rest ${ }^{138}$ (Table 7). Similarly, in an RCT of 44 Thai patients with CAD, Jatuporn et al found those receiving a 4-month yoga-based lifestyle modification program but no medication showed significant increases in blood antioxidants relative to usual care controls, although MDA levels did not differ between groups. ${ }^{100}$

Together, the 7 studies reviewed above offer support for a possible beneficial influence of yoga 
Table 7. Cross-Sectional Studies and Clinical Trials Investigating the Effects of Yoga and Yoga-Based Programs on Coagulation Profiles and Indices of Oxidative Stress, Stratified by Study Design and Intervention: Summarized Findings (Studies Reporting Beneficial Effects Are in Bold)

\begin{tabular}{|c|c|c|c|c|c|c|c|c|}
\hline \multirow[b]{3}{*}{ Findings, by Endpoint } & \multicolumn{8}{|c|}{ Study Design } \\
\hline & \multirow{2}{*}{$\begin{array}{l}\text { Cross- } \\
\text { Sectional } \\
\text { (Yoga } \\
\text { Alone) }\end{array}$} & \multirow{2}{*}{$\begin{array}{l}1 \text { to } 2 \\
\text { Sessions } \\
\text { (Yoga } \\
\text { Alone) }\end{array}$} & \multicolumn{2}{|c|}{$\begin{array}{l}\text { Uncontrolled } \\
\text { Clinical Trials } \\
\text { (>2 sessions) }\end{array}$} & \multicolumn{2}{|c|}{$\begin{array}{l}\text { Non-Randomized } \\
\text { Controlled Clinical } \\
\text { Trials ( }>2 \text { sessions) }\end{array}$} & \multicolumn{2}{|c|}{$\begin{array}{c}\text { Randomized } \\
\text { Controlled Trials } \\
(>2 \text { sessions })\end{array}$} \\
\hline & & & $\begin{array}{l}\text { Yoga } \\
\text { Alone }\end{array}$ & $\begin{array}{c}\text { Multiple } \\
\text { Interventions }\end{array}$ & $\begin{array}{l}\text { Yoga } \\
\text { Alone }\end{array}$ & $\begin{array}{c}\text { Multiple } \\
\text { Interventions }\end{array}$ & $\begin{array}{l}\text { Yoga } \\
\text { Alone }\end{array}$ & $\begin{array}{c}\text { Multiple } \\
\text { Interventions }\end{array}$ \\
\hline $\begin{array}{l}\text { Coagulation/Fibrinolytic Profiles } \\
\text { Reduced fibrinogen } \\
\text { Increased fibrinolytic activity } \\
\text { Prolonged platelet aggregation time } \\
\text { Prolonged activated partial } \\
\text { thromboplastin time }\end{array}$ & & & $\begin{array}{c}{[136]} \\
{[136]} \\
{[136] \text { (NS) }} \\
{[136](\mathrm{NS})}\end{array}$ & & & [98] & & \\
\hline $\begin{array}{l}\text { Markers of Oxidative stress } \\
\text { Increased Glutathione } \\
\text { Increased Vitamins E, C } \\
\text { Increased total antioxidants } \\
\text { Super oxide dismutase (SOD) } \\
\text { Increased } \\
\text { No change } \\
\text { Catalase } \\
\text { Increased } \\
\text { No change } \\
\text { Reduced free radicals } \\
\text { Malonyldialdehyde (MDA) } \\
\text { Reduced } \\
\text { No change }\end{array}$ & & {$[138]^{*}$} & [85] & {$[68]$} & $\begin{array}{l}{[138]} \\
{[137]} \\
{[138]} \\
{[137]}\end{array}$ & & & $\begin{array}{l}{[100]} \\
{[100]} \\
{[100]}\end{array}$ \\
\hline
\end{tabular}

${ }^{*} P<.1$; Yoga $\mathrm{PR}$ in addition to exercise vs exercise alone.

Abbreviations: NS, $P>.05$ ( $\mathrm{N}=7$ subjects).

on oxidative stress and coagulation profiles, at least in certain populations. Limitations of these studies include lack of appropriate comparison groups, ${ }^{68,85,136}$ small sample sizes, ${ }^{68,85,136,138}$ possible selection bias or uncontrolled confounding by lifestyle and other factors, ${ }^{85,98,100,136-138}$ lack of randomization, ${ }^{98,137}$ inadequate information regarding the study population, ${ }^{85,138}$ subject selection, ${ }^{136,138}$ intervention, ${ }^{138}$ or analytic methods, ${ }^{68,85,98,100,137}$ multiple interventions, ${ }^{68,100}$ and problems with data analysis or presentation. ${ }^{68,98,100,137}$ In addition, blinding of outcome assessment was not well-reported in any of the 7 studies identified.

\section{Effects of Yoga on Markers of sympathetic/parasympathetic activation and cardiovagal function}

Since 1970, numerous studies have investigated the effects of yoga on markers of sympathetic/parasympathetic activation and cardiovagal function. Our search identified a total of 42 studies from 6 countries, including 2 cross-sectional studies, 15 uncontrolled clinical trials, 16 nonrandomized controlled trials, and 9 RCTs. Findings of these studies are summarized in Table 8. Although some studies have yielded inconsistent results, over $85 \%$ offer some evidence that yoga promotes a reduction in sympathetic activation, enhancement of cardiovagal function, and a shift in autonomic nervous system balance from primarily sympathetic to parasympathetic. Key changes, reviewed briefly below, include significant reductions in respiratory and heart rate, in cortisol concentrations, catecholamine levels, and renin activity, in skin conductance, and in cardiovascular response to stress, as well as significant increases in heart rate variability and baroreflex sensitivity.

Of the 27 studies investigating the effect of yoga on heart and/or respiratory rate, only 2 studies showed no change in either index, including a nonrandomized controlled study of 10 young athletes ${ }^{113}$ and an RCT of healthy young men. ${ }^{128}$ However, both of these latter studies demonstrated improvement in other indices of cardiovascular function. In contrast, 25 eligible intervention studies reported a beneficial effect of yoga and yogabased programs on baseline respiratory rate, base- 
Table 8. Cross-Sectional Studies and Clinical Trials Investigating the Effects of Yoga and Yoga-Based Programs on Markers of Sympathetic Activation and Reactivity, Cardiovagal Function, and Cardiovascular Recovery from Stress, Stratified by Study Design and Intervention: Summarized Findings (Studies Reporting Beneficial Effects Are in

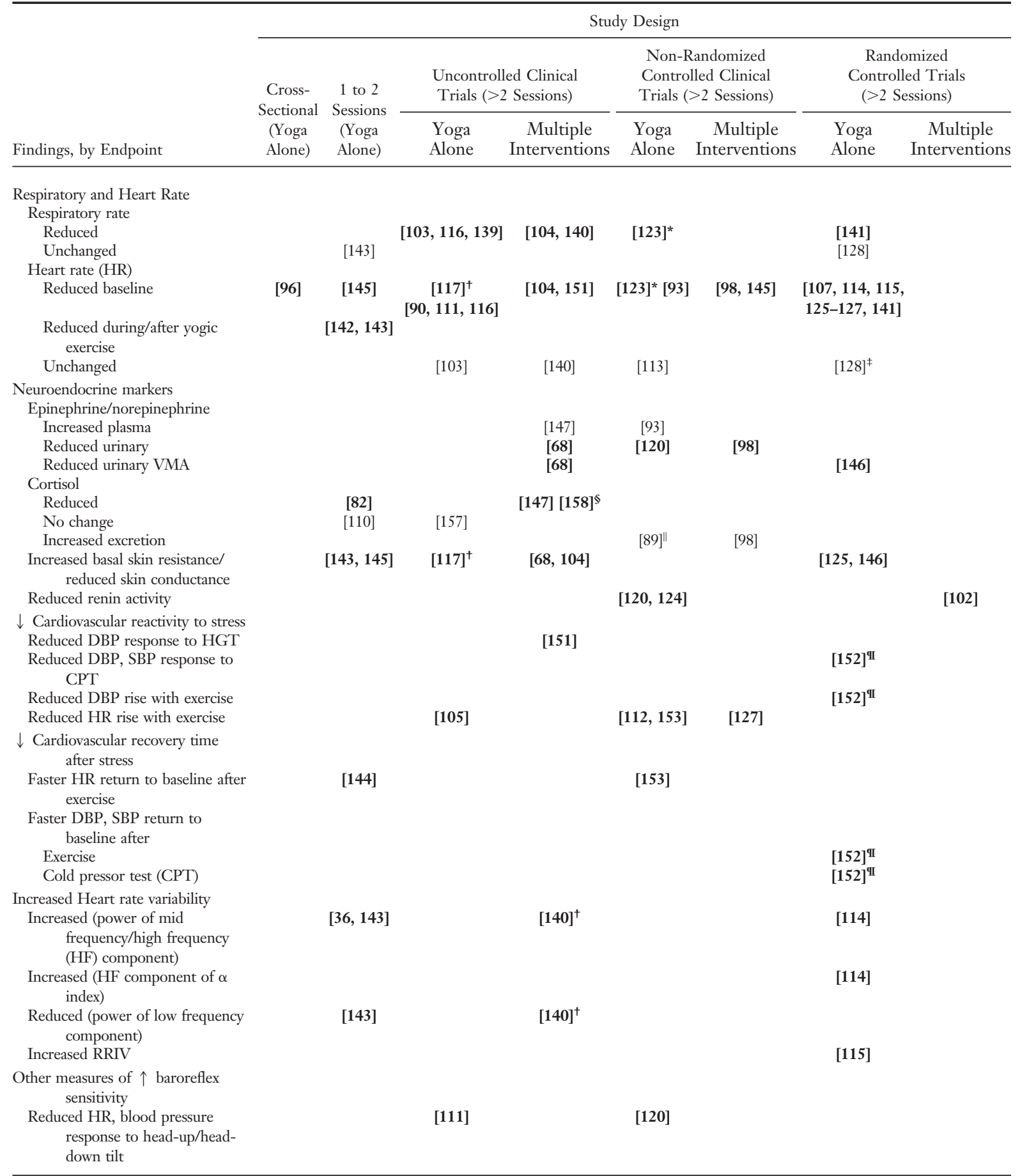

*In both hypertensive and normotensive subjects.

${ }^{\dagger}$ Only in subjects with Occupational Stress Index scores greater than the median.

"With biofeedback.

"17-hydroxy-corticosteroid.

${ }^{\$}$ Only in subjects with initial cortisol levels above the median; cortisol levels in those below the median did not change.

${ }^{\ddagger}$ Yoga PR in addition to exercise vs. exercise alone.

Abbreviations: CPT, cold pressor test; DBP, diastolic blood pressure; HGT, hand grip test; HR, heart rate; RRIV, R-R (heart rate) interval variation; SBP, systolic blood pressure; VMA, vanillylmandelic acid, a metabolite of norepinephrine. 
line heart rate, and/or heart rate after exercise (Table 8 ). Seven studies (of 8 total) have documented a $3.8 \%$ to $60.3 \%$ reduction in respiratory rate with yoga relative to baseline $e^{103,104,116,139,140}$ and/or controls receiving usual care ${ }^{123}$ or an aerobic exercise program ${ }^{141}$ (Table 5). These investigations include studies in healthy adults ${ }^{103,104,116,139,140}$ and children, ${ }^{141}$ as well as in hypertensive adults. ${ }^{123}$ Similarly, 21 of 24 total clinical trials reported a $4.3 \%$ to $38.8 \%$ decline in heart rate relative to baseline, \|\| engagement in a relaxing, nonyogic activity ${ }^{104,142-145}$ and/or controls receiving usual care, ${ }^{123}$ an aerobic exercise program,${ }^{141}$ or no intervention. ${ }^{98,115,125,127}$ These trials included studies of healthy ${ }^{\mathrm{III}}$ and hypertensive adults ${ }^{107,123}$ and of healthy children. ${ }^{15,141}$ In addition, in a cross-sectional study of healthy middle-aged men, Vyas and colleagues found those who had been practicing yoga meditation for 5 years or more to have significantly lower baseline heart rates than those who with no meditation experience. ${ }^{96}$ Of those clinical trials demonstrating positive effects, yoga practice was associated with a 3.8 to $60.3 \%$ reduction in respiratory rate and a 4.3 to $38.8 \%$ decline in heart rate (Table 5).

Although findings regarding the effects of yoga on cortisol levels have been inconsistent, probably due in part to differing collection times and measurement methods, those regarding the influence of yoga on other neuroendocrine indices of sympathetic activation have been remarkably consistent overall (Table 8). Of the 13 studies investigating the influence of yoga practice on catecholamine levels, renin activity, and/or basal skin conductivity, 11 have demonstrated significant reductions in these markers of sympathoadrenal activation. These studies include investigations of healthy populations $98,104,125,143,145$ and those with hypertension ${ }^{68,102,117,120,124}$ or epilepsy. ${ }^{146}$ Only 2 small uncontrolled studies of healthy Indian adults, conducted by the same group of investigators in the 1970s, have yielded contradictory results. ${ }^{93,147}$ With respect to catecholamine levels, 4 of the 6 eligible studies identified demonstrated significant declines in 24 hour urinary catecholamines among yoga program participants when compared with baseline $^{68}$ or to controls receiving usual care, ${ }^{146}$

\footnotetext{
"I See References 90, 93, 104, 111, 116, 117, 125, 126

IIISee References 90, 93, 98, 104, 111, 114, 116, 117, $125-127,142-145$.
}

sham yoga, ${ }^{146}$ or no intervention. ${ }^{98}$ Studies evaluating the possible effects of yoga on renin activity and basal skin conductance have yielded even more consistent findings; of the 3 studies examining the former, and 7 studies investigating the latter endpoints, all documented significant reductions in these markers with yoga practice alone ${ }^{* * *}$ or in combination with lifestyle education. ${ }^{68,102}$

Consistent with these results, findings from several studies suggest that yoga practice can lead to improvement in both cardiovascular reactivity to stress and cardiovascular recovery from stress ( $\mathrm{Ta}-$ ble 8). Cardiovascular reactivity to stress, a factor strongly associated with insulin resistance ${ }^{148,149}$ is also a major independent predictor of hypertension, stroke, myocardial infarction, and cardiovascular mortality ${ }^{31}$; cardiovascular recovery from stress is a marker of vagal rebound that has likewise been strongly associated with CVD risk. ${ }^{150}$ Documented changes associated with the practice of yoga and yoga-based programs in the 7 eligible studies identified include: (1) significantly reduced blood pressure and heart rate responses to stress relative to baseline $\mathrm{e}^{105,151}$ or controls receiving nonyogic exercise, ${ }^{112}$ usual care, ${ }^{152}$ or no interven$\operatorname{tion}^{127,153}$; and (2) accelerated cardiovascular recovery time from stress compared with nonyoga resting poses ${ }^{144}$ or controls receiving usual care $e^{152}$ or no intervention. ${ }^{153}$

Finally, 7 recent studies in Indian ${ }^{111,115,120,140}$ and European ${ }^{36,114}$ populations suggest that participating in yoga and yoga-based programs can improve heart rate variability and baroreflex sensitivity in both healthy ${ }^{36,111,114,115,140,143}$ and hypertensive populations ${ }^{120}$ (Table 8). Low heart rate variability (HRV) and baroreflex sensitivity reflect impaired cardiovagal adaptability and suggest excessive sympathetic and/or insufficient parasympathetic tone..$^{60,154,155}$ These alterations are, in turn, strong independent predictors of cardiovascular morbidity and mortality ${ }^{21,29,36}$ and are thought to mediate in part the effect of IRS-related abnormalities on these outcomes. ${ }^{21,156}$ In contrast, high HRV and baroreflex sensitivity are generally considered to indicate good cardiovagal adaptability and sympathovagal balance, ${ }^{155}$ permitting greater responsivity and sensitivity to changing environmental demands.

***See References 104, 117, 120, 124, 125, 143, 145, 146. 
Collectively, this research suggests that even the short-term practice of yoga may produce marked reductions in sympathoadrenal activation, enhance cardiovagal tone, and promote sympathovagal balance. Several studies have demonstrated pronounced changes in markers of sympathetic/parasympathetic activity within a single yoga session (Table 8); others have documented significant beneficial alterations in baseline measurements in as little as 2 days in uncontrolled trials, ${ }^{140} 3$ weekly sessions in nonrandomized controlled trials, ${ }^{126}$ and 8 days ${ }^{131}$ in RCTs. Interventions associated with improvement in markers of sympathetic/parasympathetic activity and cardiovagal function include yoga routines both alone $(\mathrm{N}=29)$ and in combination with other therapies $(\mathrm{N}=10)$; of those studies using yoga alone, 16 incorporated active yoga asanas, 7 used relaxation postures alone or in combination with meditation, and 5 used meditation or breathing exercises alone (Table 3).

Although evidence for a beneficial influence of yoga on sympathovagal balance is remarkably consistent overall across this diverse array of studies, many studies have limitations that hinder conclusive interpretation of findings. Many had no comparison groups, ${ }^{\dagger \dagger}$ small sample sizes ${ }^{\ddagger \neq \dagger}$ and/or comparison groups that differed in baseline characteristics. ${ }^{96,98,110,120,142,146,153}$ Over $50 \%$ of the studies identified had 25 or fewer subjects, and over $20 \%$ had less than 15 . Others lacked detailed information on eligibility criteria and population characteristics, ${ }^{\$ \$ \$}$ treatment allocation, ${ }^{113,124}$ and analytic methods, "| || and blinding of the outcome assessment was well reported in only a few studies. ${ }^{115,128}$ In others, loss to follow-up, ${ }^{105,114,116,146,157,158}$ variable exposure to or experience with the intervention, ${ }^{82,96,110-112,118,142-144}$ potential selection bias, ${ }^{\text {,IIII }}$ and uncontrolled confounding factors ${ }^{* * *}$ may have been important. The yoga intervention was not well described in some studies, ${ }^{12,124,147,152}$ and several used multiple inter-

\footnotetext{
${ }^{+\dagger}$ See References 68, 82, 89, 90, 103-105, 111, 116-118, $139,140,147,151,157,158$.

${ }^{\text {寻 }}$ See References 36, 68, 82, 89, 90, 93, 103, 105, 110, $111,113,115-117,120,124,125,142,145,147,151,153$. ${ }^{\$} \$$ See References 82, 89, 90, 93, 104, 107, 112, 115, 117, 123, 139-142, 147, 151-153.

"II" ISee References 68, 82, 90, 93, 98, 102, 105, 111-113, $116-118,123,125,144,147$.

IIIIISee References 96, 98, 105, 110, 117, 145, 146, 153.

****See References 93, 96, 98, 103, 107, 110-113, 115, $118,120,124-127,139,153,157$.
}

ventions. $^{\text {t+† }}$ Other methodological problems included lack of randomization ${ }^{\ddagger \neq \neq \neq}$ or description of the randomization process, $\$ \mathbb{S} \mathbb{S} \mathbb{S}$ inadequate data analysis or presentation, ${ }^{68,89,93,98,112,117,123}$ multiple comparisons, ${ }^{\|||||||}$or absence of appropriate intergroup comparisons. ${ }^{\text {IIITITI. }}$

\section{Effects of Yoga on Clinical Endpoints}

Several studies in Indian, ${ }^{68,78,80,91,92,109,119}$ European, ${ }^{79,95,121,122,129,130}$ and American populations ${ }^{87}$ have suggested that yoga may also be helpful in the management of CVD and other IRS-related chronic conditions. Our search identified a total of 14 eligible studies evaluating the influence of yoga and yoga-based interventions on clinical endpoints, including 4 uncontrolled trials, 4 nonrandomized controlled studies, and 6 RCTs (Table 9). In uncontrolled Indian studies of adults with hyperten$\operatorname{sion}^{68,119}$ and/or diabetes, ${ }^{68,91,92}$ completion of a simple ${ }^{91,119}$ or comprehensive yoga program ${ }^{68,92}$ was associated with a markedly reduced need for medication relative to baseline. In agreement with these findings, controlled studies of adults with hypertension ${ }^{109,121,122,130}$ risk factors for $\mathrm{CVD}^{79}$ and/or CAD ${ }^{80}$ and diabetes ${ }^{95}$ showed a decline in need for drug therapy among those enrolled in a yoga-based intervention compared with controls receiving usual care, ${ }^{95}$ enhanced usual care,${ }^{79,109,121,122}$ usual care plus a diet and exercise program, ${ }^{80}$ or placebo therapy. ${ }^{130}$ Controlled studies in Indian, ${ }^{78}$ British, ${ }^{79}$ and American ${ }^{87}$ populations also suggest that yoga-based programs may attenuate signs, reduce complications, and improve the prognosis of those with frank or underlying disease. For example, in an RCT of Indian men with CAD, those enrolled in a 12 -month comprehensive yoga program showed retardation of coronary atherosclerosis, increased regression and reduced progression of vascular lesions, and reduced anginal episodes relative to usual care controls ${ }^{78}$; another, nonrandomized controlled study of CAD patients yielded similar results. ${ }^{80}$ In a group of generally healthy

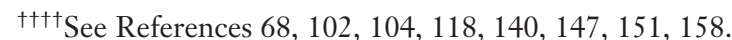

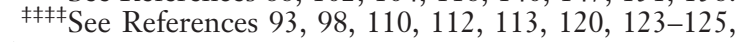
153.

$\$ \$ \$ \$ S$ See References 102, 107, 114, 115, 127, 141, 152.

\|\|\|\| See References 68, 90, 98, 104, 105, 110,111, 113, $115,116,123,125,127,139,140,142,144,151,152,157,158$. đIIII See References $93,112,114,115,120,123,128,141$, $143,153$. 
Table 9. Clinical Trials (>2 Sessions) Investigating the Effects of Yoga and Yoga-Based Programs on Clinical Outcomes, Stratified by Study Design and Intervention (Yoga, Including Yoga-Based Meditation Alone vs. in Combination with Other Interventions) (Studies Reporting Beneficial Effects Are in Bold)

\begin{tabular}{|c|c|c|c|c|c|c|}
\hline \multirow[b]{3}{*}{ Findings, by Endpoint } & \multicolumn{6}{|c|}{ Study Design } \\
\hline & \multicolumn{2}{|c|}{$\begin{array}{l}\text { Uncontrolled } \\
\text { Clinical Trials }\end{array}$} & \multicolumn{2}{|c|}{$\begin{array}{l}\text { Non-Randomized } \\
\text { Controlled Trials }\end{array}$} & \multicolumn{2}{|c|}{$\begin{array}{c}\text { Randomized } \\
\text { Controlled Trials }\end{array}$} \\
\hline & $\begin{array}{l}\text { Yoga } \\
\text { Alone }\end{array}$ & $\begin{array}{c}\text { Multiple } \\
\text { Interventions }\end{array}$ & $\begin{array}{l}\text { Yoga } \\
\text { Alone }\end{array}$ & $\begin{array}{c}\text { Multiple } \\
\text { Interventions }\end{array}$ & $\begin{array}{l}\text { Yoga } \\
\text { Alone }\end{array}$ & $\begin{array}{c}\text { Multiple } \\
\text { Interventions }\end{array}$ \\
\hline $\begin{array}{l}\text { Clinical endpoints } \\
\text { Reduced need for medication } \\
\text { Hypertension/CAD } \\
\text { Diabetes } \\
\text { Reduced revascularization procedures related } \\
\text { complications }^{\dagger} \\
\text { Number of subjects on treatment for: }^{\text {Hypertension (no difference) }}{ }^{\dagger} \\
\text { Other CVD complications (reduced) }^{\dagger} \\
\text { Reduced ECG evidence of ischemia } \\
\text { Reduction in anginal episodes } \\
\text { Reduced carotid intimal media thickness } \\
\text { Reduced progression of CAD } \\
\text { Increased regression of CAD } \\
\text { Reduced number of serious coronary events } \\
\text { Reduced number of hospitalizations }\end{array}$ & $\begin{array}{c}{[119]} \\
{[91]}\end{array}$ & $\begin{array}{c}{[68]} \\
{[92][68]}\end{array}$ & {$[109,121,122]^{*}$} & $\begin{array}{l}{[80]} \\
{[80]} \\
{[80]}\end{array}$ & $\frac{[130]^{*}}{[95]}$ & $\begin{array}{c}{[79]^{\dagger}} \\
{[79]^{\dagger}} \\
{[79]^{+}} \\
{[79]^{\dagger}[78]} \\
{[87]} \\
{[78]} \\
{[78]} \\
{[129](N S)[79]^{\dagger}}\end{array}$ \\
\hline
\end{tabular}

*With biofeedback.

${ }^{\dagger}$ At 4 year follow up of individuals at risk for CVD; no difference in number of Ss currently on treatment for hypertension.

Abbreviations: CAD, coronary artery disease; CVD, cardiovascular disease.

American seniors, those completing a 12 -month comprehensive yoga-based program demonstrated a decline in carotid intimal media thickness, an indicator of carotid atherosclerosis, relative to those receiving usual care or a comprehensive medical, diet, and exercise intervention ${ }^{87}$; the decline was correlated inversely with adherence, suggesting a direct relation between the practice of this program and atherosclerotic change. There is also some evidence that the clinical benefits observed following yoga-based programs might persist long term. In a 4-year follow-up of an earlier RCT in hypertensive adults, Patel et al found that those who had participated in an 8-week comprehensive yoga relaxation program were less likely than usual care controls to be receiving treatment for CVDrelated complications, to have experienced a serious coronary event, or to have electrocardiographic evidence of ischemia. ${ }^{79}$

Although promising, several of these studies have methodologic and other limitations, including absence of control groups, ${ }^{119,68,91,92}$ small sample sizes, ${ }^{68,95,109,119}$ lack of randomization, ${ }^{109,121,122}$ loss to follow-up, ${ }^{80,121,122}$ possible uncontrolled confounding factors, ${ }^{91,92,95,109,119}$ unclear statistical analyses, ${ }^{68,91}$ or absence of intergroup comparisons, ${ }^{109,122}$ multiple comparisons, ${ }^{68,87,91,109}$ appar- ent lack of blinded outcome assessment, ${ }^{* * * *}$ and multiple interventions. ${ }^{68,78-80,87,92,129,130}$ Several lacked adequate descriptions of the study population, ${ }^{80,91,109,119,121,130}$ sample selection process, ${ }^{119}$ intervention, ${ }^{121}$ treatment allocation, ${ }^{80}$ or statistical methods. ${ }^{\dagger+t \dagger}$ In addition, reporting bias may have resulted in omission of negative findings, possibly inflating the apparent positive effect of yoga on clinical endpoints.

\section{Yoga, Psychosocial Risk Factors for CVD, and Possible Underlying Mechanisms}

Although methodologic and other limitations of many studies preclude drawing firm conclusions, the almost 70 investigations reviewed above nonetheless offer evidence that yoga may have a beneficial influence on many IRS-related risk factors for CVD, may improve clinical outcomes, and may aid in the management of CVD and other IRS-related conditions. In addition, a growing number of studies from both Western and non-Western countries suggest that yoga therapy may be effective in reducing psychosocial risk factors for CVD as well.

***** See References 68, 79, 80, 91, 92, 109, 119, 121, 122.

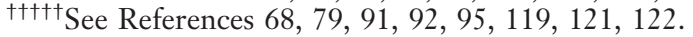




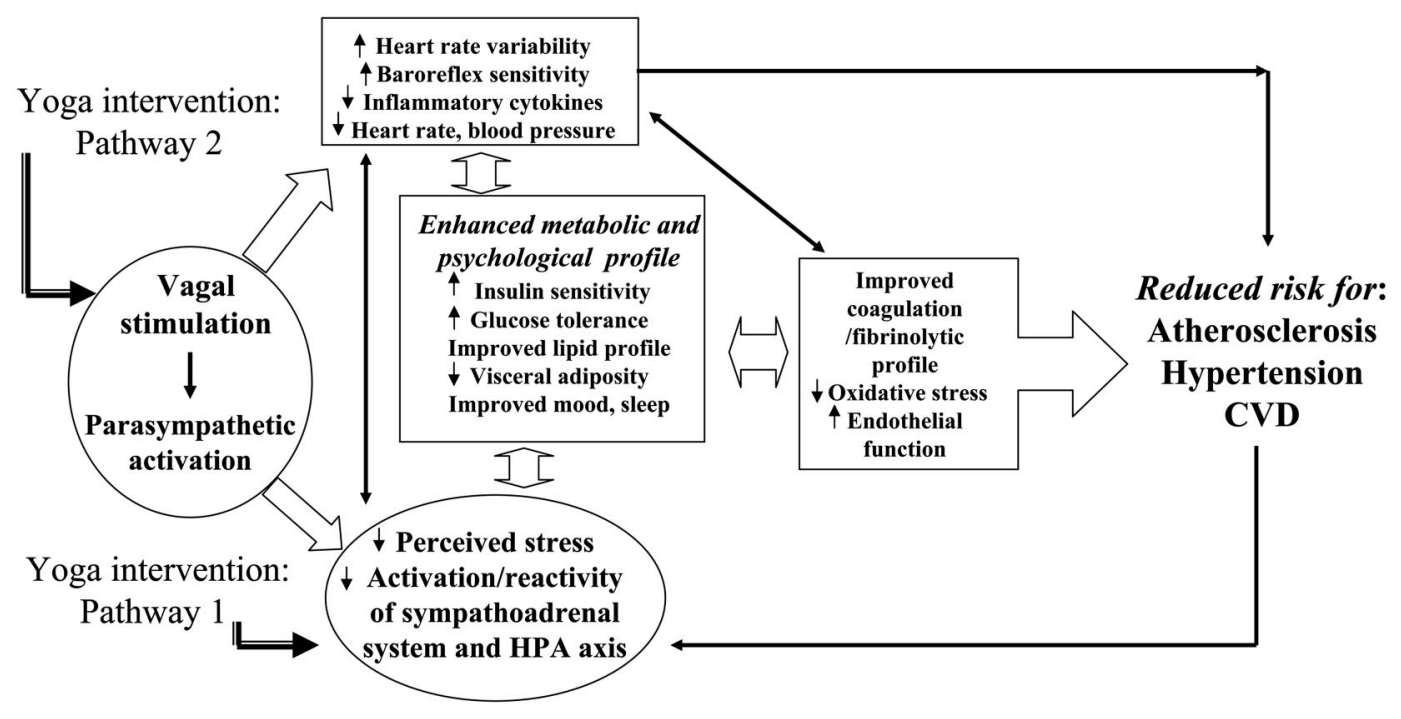

Figure 1. Hypothesized Pathways by Which Yoga Intervention May Enhance Cardiovascular Risk Profiles

For example, yoga has been reported to decrease perceived stress ${ }^{109,159,160}$ and reactivity to stressors ${ }^{110}$ enhance stress-related coping, ${ }^{161}$ reduce symptoms of depression ${ }^{127,128,162-165}$ and anxiety, ${ }^{66,127,161,162,166,167}$ and decrease anger, ${ }^{162,168}$ tension, and fatigue. ${ }^{162,169}$ Likewise, recent studies in India ${ }^{66,159,170}$ and the United States ${ }^{171}$ have indicated that yoga practice may improve sleep in both healthy ${ }^{66,159}$ and chronically ill populations. ${ }^{170,171}$

Although the mechanisms underlying the putative beneficial effects of yoga therapy on cardiovascular risk profiles are not yet well understood, the observed changes probably occur primarily through 2 pathways. First, by reducing the activation and reactivity of the sympathoadrenal system and the hypothalamic pituitary adrenal (HPA) axis and promoting feelings of well-being, yoga may alleviate the effects of stress and foster multiple positive downstream effects on neuroendocrine status, metabolic function and related inflammatory responses (Figure 1, pathway 1). Second, by directly stimulating the vagus nerve, yoga may enhance parasympathetic output and thereby shift the autonomic nervous system balance from primarily sympathetic to parasympathetic, leading to positive changes in cardiac-vagal function, in mood and energy state, and in related neuroendocrine, metabolic, and inflammatory responses (Figure 1, pathway 2). Yoga may also provide a positive source of social support, a factor strongly associated with CVD risk, ${ }^{32,38}$ may aid in improving health-related attitudes and lifestyle choices, in part by enhancing psychological well-being, ${ }^{38}$ and in this way may play an important role in CVD prevention and health promotion. ${ }^{38}$

\section{Summary and Conclusions}

In summary, a substantial body of published research suggests that yoga may be instrumental in improving core indices of the IRS, including glucose tolerance and insulin sensitivity, lipid profiles, anthropometric characteristics, and blood pressure in a both healthy populations and those with chronic IRS-related conditions. In addition, more limited data indicate that yoga may improve coagulation profiles, at least in healthy populations, and reduce oxidative stress in both healthy adults and populations with serious chronic disorders. There is also mounting evidence to suggest that yoga may reduce sympathetic activation and enhance cardiovagal function, factors strongly associated with both IRS and CVD risk. In addition, findings from several studies, including several recent controlled trials, ${ }^{78,80,87}$ indicate that yoga may be useful in the management of CVD and related conditions, and in the prevention of CVD in those at risk.

However, despite the growing popularity and apparent therapeutic potential of yoga in the prevention and management of CVD, and the now considerable body of published literature on this topic, relatively few rigorous, controlled studies have been conducted on the effects of yoga on 
physiologic and anthropometric indices of cardiovascular risk; even fewer have been conducted in western populations. Since 1970, approximately $70 \%$ of clinical trials investigating the effects of yoga practice on CVD disease risk and clinical outcomes have been conducted in Indian populations, for whom yoga is an integral part of a longstanding cultural and spiritual tradition. Interpretation of many existing studies is also limited by small sample sizes, lack of appropriate control groups, inadequate description of methods, selection bias, failure to adjust for lifestyle characteristics and other potential confounders, exposure to multiple interventions, inadequacies in statistical analysis and presentation, or other methodological problems. In many of the controlled trials, treatment allocation was not randomized, and direct statistical comparisons were not made to control groups, potentially biasing the findings. In addition, the large variation in the nature, duration, intensity, and delivery methods of the yoga-based interventions used, even among studies using yoga practice alone, renders comparison across studies difficult. Publication bias may also play a role in the selective reporting of positive results, ${ }^{172}$ particularly in non-Western countries, where yoga is more widely embraced and more likely to be incorporated into medical treatment. Although existing RCTs have yielded results consistent overall with those of nonrandomized and uncontrolled studies, suggesting that the positive findings of these latter studies do not simply reflect bias because of poor study design, clearly, additional high quality RCTs are warranted. Specifically, rigorous, well-designed studies are needed to elucidate the effects of standardized yoga programs on IRS-related indices of CVD risk and related clinical endpoints, especially in American and other Western populations that remain underrepresented in the current literature.

We thank Dr. Ada Jacox for very helpful comments on an earlier draft of this article.

\section{References}

1. American Heart Association, 2004 Heart and Stroke Statistical Update. American Heart Association, 2004.

2. Bonow RO. Primary prevention of cardiovascular disease: a call to action. Circulation 2002;106: 3140-1.

3. Lopez-Candales A. Cardiovascular diseases: a re- view of the Hispanic perspective. Awareness is the first step to action. J Med 2002;33:227-45.

4. Watkins LO. Epidemiology and burden of cardiovascular disease. Clin Cardiol 2004;27(6 Suppl 3): III2-6.

5. Pramparo P. The epidemiology of hypertension in South America. J Hum Hypertens 2002;16(Suppl 1):S3-6.

6. Posner B, Franz M, Quatromoni P. Nutrition and the global risk for chronic diseases: the INTERHEALTH Nutrition Initiative. Nutr Rev 1994;52: 210-7.

7. Popkin B. The nutrition transition in low-income countries. Nutr Rev 1994;52:285-98.

8. Grundy S. Hypertriglyceridemia, insulin resistance, and the metabolic syndrome. Am J Cardiol 1999; $83: 25 \mathrm{~F}-9 \mathrm{~F}$.

9. Ginsberg H. Insulin resistance and cardiovascular disease. J Clin Invest 2000;106:453-8.

10. Isomaa B. A major health hazard: the metabolic syndrome. Life Sci 2003;73:2395-411.

11. Reilly M, Rader D. The metabolic syndrome: more than the sum of its parts? Circulation 2003;108: 1546-51.

12. Reaven G, Abbasi F, McLaughlin T. Obesity, insulin resistance, and cardiovascular disease. Recent Prog Horm Res 2004;59:207-23.

13. Juhan-Vague I, Morange PE, Alessi MC. The insulin resistance syndrome: implications for thrombosis and cardiovascular disease. Pathophysiol Haemostasis Thromb 2002;32:269-73.

14. Ginsberg HN, Huang LS. The insulin resistance syndrome: impact on lipoprotein metabolism and atherothrombosis. J Cardiovasc Risk 2000;7:32531.

15. Natali A, Ferrannini E. Hypertension, insulin resistance, and the metabolic syndrome. Endocrinol Metab Clin North Am 2004;33:417-29.

16. Wheatcroft SB, Williams IL, Shah AM, Kearney MT. Pathophysiological implications of insulin resistance on vascular endothelial function. Diabetic Med 2003;20:255-68.

17. Hsueh $W$, Lyon C, Quinones M. Insulin resistance and the endothelium. Am J Med 2004;117:109-17.

18. Fernandez-Real JM, Ricart W. Insulin resistance and chronic cardiovascular inflammatory syndrome. Endo Rev 2003;24:278-301.

19. Byrne CD. Programming other hormones that affect insulin. Br Med Bull 2001;60:153-71.

20. Innes K, Wimsatt J. Pregnancy-induced hypertension and insulin resistance: evidence for a connection. Acta Obstet Gynecol Scand 1999;78:263-84.

21. Gadegbeku CA, Dhandayuthapani A, Sadler ZE, Egan BM. Raising lipids acutely reduces baroreflex sensitivity. American Journal of Hypertension 2002;15:479-85.

22. Beske SD, Alvarez GE, Ballard TP, Davy KP. Re- 
duced cardiovagal baroreflex gain in visceral obesity: implications for the metabolic syndrome. Am J Physiol 2002;282:H630-5.

23. Pikkujamsa SM, Huikuri HV, Airaksinen KE, Rantala AO, Kauma H, Lilja M, et al. Heart rate variability and baroreflex sensitivity in hypertensive subjects with and without metabolic features of insulin resistance syndrome. Am J Hypertens 1998; 11:523-31.

24. Bjorntorp P, Holm G, Rosmond R. Hypothalamic arousal, insulin resistance and type 2 diabetes mellitus. Diabetic Med 1999;16:373-83.

25. Egan BM. Insulin resistance and the sympathetic nervous system. Curr Hypertens Rep 2003;5:24754.

26. Esler M. The sympathetic system and hypertension. Am J Hypertens 2000;13:99S-105S.

27. Palatini P. Sympathetic overactivity in hypertension: a risk factor for cardiovascular disease. Curr Hypertens Rep 2001;3(Suppl 1):S3-9.

28. Rozanski A, Blumenthal JA, Kaplan J. Impact of psychological factors on the pathogenesis of cardiovascular disease and implications for therapy. Circulation 1999;99:2192-217.

29. Singh RB, Kartik C, Otsuka K, Pella D, Pella J. Brain-heart connection and the risk of heart attack. Biomed Pharmacother 2002;56(Suppl 2):257s-65s.

30. Everson SA, Lynch JW, Chesney MA, et al. Interaction of workplace demands and cardiovascular reactivity in progression of carotid atherosclerosis: population based study. BMJ 1997;314:553-8.

31. Jennings JR, van der Molen MW, Somsen RJ, Graham R, Gianaros PJ. Vagal function in health and disease: studies in Pittsburgh. Physiol Behav 2002; 77:693-8.

32. Bunker SJ, Colquhoun DM, Esler MD, et al. "Stress" and coronary heart disease: psychosocial risk factors. Med J Aust 2003;178:272-6.

33. Bjorntorp P, Holm G, Rosmond R, Folkow B. Hypertension and the metabolic syndrome: closely related central origin?. Blood Pressure 2000;9:7182.

34. Hjemdahl P. Stress and the metabolic syndrome: an interesting but enigmatic association. Circulation 2002;106:2634-6.

35. Brunner EJ, Hemingway H, Walker BR, et al. Adrenocortical, autonomic, and inflammatory causes of the metabolic syndrome: nested case-control study. Circulation 2002;106:2659-65.

36. Bernardi L, Sleight P, Bandinelli G, et al. Effect of rosary prayer and yoga mantras on autonomic cardiovascular rhythms: comparative study. BMJ 2001; 323:1446-9.

37. Bjorntorp P. Body fat distribution, insulin resistance, and metabolic diseases. Nutrition 1997;13: 795-803.

38. Vitaliano PP, Scanlan JM, Zhang J, Savage MV, Hirsch IB, Siegler IC. A path model of chronic stress, the metabolic syndrome, and coronary heart disease. Psychosom Med 2002;64:418-35.

39. Weber B, Schweiger U, Deuschle M, Heuser I. Major depression and impaired glucose tolerance. Exp Clin Endocrinol Diabetes 2000;108:187-90.

40. Okamura F, Tashiro A, Utumi A, Imai T, Suchi T, Tamura D, et al. Insulin resistance in patients with depression and its changes during the clinical course of depression: minimal model analysis. Metabolism 2000;49:1255-60.

41. Raikkonen K, Matthews KA, Kuller LH. The relationship between psychological risk attributes and the metabolic syndrome in healthy women: antecedent or consequence? Metabolism 2002;51:1573-7.

42. Lucini D, Norbiato G, Clerici M, Pagani M. Hemodynamic and autonomic adjustments to real life stress conditions in humans. Hypertension 2002;39: 184-8.

43. Levenstein S, Smith M, Kaplan G. Psychosocial predictors of hypertension in men and women. Arch Intern Med 2001;161:1341-6.

44. Pickering T, Clemow L, Davidson K, Gerin W. Behavioral cardiology - has its time finally arrived? Mt Sinai J Med 2003;70:101-12.

45. Davidson K, Jonas B, Dixon K, Markovitz J. Do depression symptoms predict early hypertension incidence in young adults in the CARDIA study? Coronary Artery Risk Development in Young Adults. Arch Int Med 2000;160:1495-500.

46. Ariyo A, Haan M, Tangen C, et al. Depressive symptoms and risks of coronary heart disease and mortality in elderly Americans. Cardiovascular Health Study Collaborative Research Group. Circulation 2000;102:1773-91.

47. Chen CC, Lu FH, Wu JS, Chang CJ. Correlation between serum lipid concentrations and psychological distress. Psychiatry Res 2001;102:153-62.

48. Spieker LE, Hurlimann D, Ruschitzka F, et al. Mental stress induces prolonged endothelial dysfunction via endothelin-A receptors. Circulation 2002;105:2817-20.

49. Cannon RO 3rd. Role of nitric oxide in cardiovascular disease: focus on the endothelium. Clin Chem 1998;44:1809-19. Erratum in: Clin Chem 1998;44: 2070.

50. Sherwood A, Johnson K, Blumenthal JA, Hinderliter AL. Endothelial function and hemodynamic responses during mental stress. Psychosomatic Medicine 1999;61:365-70.

51. Eaton W, Armenian H, Gallo J, Pratt L, Ford D. Depression and risk for onset of type II diabetes. A prospective population-based study. Diabetes Care 1996;19:1097-102.

52. Black PH, Garbutt LD. Stress, inflammation and cardiovascular disease. J Psychosom Res 2002;52:123.

53. von Kanel R, Mills PJ, Fainman C, Dimsdale JE. Effects of psychological stress and psychiatric dis- 
orders on blood coagulation and fibrinolysis: a biobehavioral pathway to coronary artery disease? Psychosom Med 2001;63:531-44.

54. Goodman E, Whitaker R. A prospective study of the role of depression in the development and persistence of adolescent obesity. Pediatrics 2002;110: 497-504.

55. Nelson TL, Palmer RF, Pedersen NL, Miles TP. Psychological and behavioral predictors of body fat distribution: age and gender effects. Obes Res 1999; 7:199-207.

56. Everson SA, Kaplan GA, Goldberg DE, Salonen R, Salonen JT. Hopelessness and 4-year progression of carotid atherosclerosis. The Kuopio Ischemic Heart Disease Risk Factor Study. Arterioscler Thromb Vasc Biol 1997;17:1490-5.

57. Greenwood DC, Muir KR, Packham CJ, Madeley RJ. Coronary heart disease: a review of the role of psychosocial stress and social support. J Public Health Med 1996;18:221-31.

58. Kop WJ. The integration of cardiovascular behavioral medicine and psychoneuroimmunology: new developments based on converging research fields. Brain Behav Immun 2003;17:233-7.

59. Todaro JF, Shen BJ, Niaura R, Spiro A 3rd, Ward KD. Effect of negative emotions on frequency of coronary heart disease (The Normative Aging Study). Am J Cardiol 2003;92:901-6.

60. Carney RM, Freedland KE, Miller GE, Jaffe AS. Depression as a risk factor for cardiac mortality and morbidity: a review of potential mechanisms. J Psychosom Res 2002;53:897-902.

61. Davidson D. Preventive cardiology. Baltimore, 1991.

62. Carr MC. The emergence of the metabolic syndrome with menopause. J Clin Endocrinol Metab 2003;88:2404-11.

63. Ford ES, Giles WH, Mokdad AH. Increasing prevalence of the metabolic syndrome among U.S. adults. Diabetes Care 2004;27:2444-9.

64. Seidell JC. Obesity, insulin resistance and diabetes-a worldwide epidemic. Br J Nutr 2000;83 Suppl 1:S5-8.

65. Lindsay R, Howard B. Cardiovascular risk associated with the metabolic syndrome. Curr Diabetes Rep 2004;4:63-8.

66. Telles S, Naveen K. Yoga for rehabilitation: an overview. Indian J Med Sci 1997;51:123-7.

67. Pandya D, Vyas V, Vyas S. Mind-body therapy in the management and prevention of coronary disease. Compr Ther 1999;25:283-93.

68. Damodaran A, Malathi A, Patil N, Shah N, Suryavansihi Marathe S. Therapeutic potential of yoga practices in modifying cardiovascular risk profile in middle aged men and women. J Assoc Physicians India 2002;50:633-40.

69. Sahay B, Sahay R. Lifestyle modification in man- agement of diabetes mellitus. J Indian Med Assoc 2002;100:178-80.

70. Garfinkel M, Schumacher HJ. Yoga. Rheum Dis Clin N Am 2000;26:125-32.

71. Chandler K. The emerging field of yoga therapy. Hawaii Med J 2001;60:286-7.

72. Raub J. Psychophysiologic effects of Hatha Yoga on musculoskeletal and cardiopulmonary function: a literature review. J Altern Complementary Med 2002;8:797-812.

73. Saper R, Eisenberg D, Davis R, Culpepper L, Phillips R. Prevalence and patterns of adult yoga use in the United States: results of a national survey. Altern Ther Health Med 2004;10:44-9.

74. Labarthe D, Ayala C. Nondrug interventions in hypertension prevention and control. Cardiol Clin 2002;20:249-63.

75. Gimbel M. Yoga, meditation, and imagery: clinical applications. Nurse Practitioner Forum 1998;9: 243-55.

76. Wood C. Mood change and perceptions of vitality: a comparison of the effects of relaxation, visualization and yoga. J Roy Soc Med 1993;86:254-8.

77. Miller J, Fletcher K, Kabat-Zinn J. Three-year follow-up and clinical implications of a mindfulness meditation-based stress reduction intervention in the treatment of anxiety disorders. Gen Hosp Psychiatry 1995;17:192-200.

78. Manchanda S, Narang R, Reddy K, et al. Retardation of coronary atherosclerosis with yoga lifestyle intervention. J Assoc Physicians India 2000;48:68794.

79. Patel C, Marmot M, Terry D, Carruthers M, Hunt B, Patel $M$. Trial of relaxation in reducing coronary risk: four year follow-up. Br Med J 1985;290:1103-6.

80. Yogendra J, Yogendra H, Ambardekar S, et al. Beneficial effects of yoga lifestyle on reversibility of ischaemic heart disease: Caring Heart Project of International Board of Yoga. J Assoc Physicians India 2004;52:283-9.

81. King MS, Carr T, D'Cruz C. Transcendental meditation, hypertension and heart disease. Aust Fam Physician 2002;31:164-8.

82. Kamei T, Toriumi Y, Kimura H, Ohno S, Kumano $\mathrm{H}$, Kimura K. Decrease in serum cortisol during yoga exercise is correlated with alpha wave activation. Percept Mot Skills 2000;90:1027-32.

83. Wang C, Collet JP, Lau J. The effect of Tai Chi on health outcomes in patients with chronic conditions: a systematic review. Arch Intern Med 2004; 164:493-501.

84. Verhagen AP, Immink $M$, van der Meulen A, Bierma-Zeinstra SM. The efficacy of Tai Chi Chuan in older adults: a systematic review. Fam Pract 2004;21:107-13.

85. Singh S, Malhotra V, Singh K, Sharma S. A preliminary report on the role of yoga asanas on oxi- 
dative stress in non-insulin dependent diabetes. Indian J Clin Biochem 2001;16:216-20.

86. Malhotra V, Singh S, Singh K, Gupta P, Sharma S, Madhu S, et al. Study of yoga asanas in assessment of pulmonary function in NIDDM patients. Indian J Physiol Pharmacol 2002;46:313-20.

87. Fields JZ, Walton KG, Schneider RH, et al. Effect of a multimodality natural medicine program on carotid atherosclerosis in older subjects: a pilot trial of Maharishi Vedic Medicine. Am J Cardiol 2002; 89:952-8.

88. Naruka J, Mathur R, Mathur A. Effect of pranayama practices on fasting blood glucose and serum cholesterol. Indian J Med Sci 1986;40:149_ 52.

89. Udupa KN, Singh RH. The scientific basis of yoga. JAMA 1972;220:1365.

90. Joseph S, Sridharan K, Patil S, et al. Study of some physiological and biochemical parameters in subjects undergoing yogic training. Indian J Med Res 1981;74:120-4.

91. Divekar M, Bhat M, Mulla A. Effect of yoga therapy in diabetes and obesity. J Diab Assoc Ind 1978; 17:75-8.

92. Jain S, Uppal A, Bhatnagar S, Talukdar B. A study of response pattern of non-insulin dependent diabetics to yoga therapy. Diabetes Res Clin Pract 1993;19:69-74.

93. Udupa KN, Singh RH, Settiwar RM. Physiological and biochemical studies on the effect of yogic and certain other exercises. Indian J Med Res 1975;63: 620-4.

94. Sahay BK, Sadasivudu B, Yogi R, et al. Biochemical parameters in normal volunteers before and after yogic practices. Indian J Med Res 1982;76(Suppl): 144-8.

95. Monro R, Power J, Coumar A, Dandona P. Yoga therapy for NIDDM: a controlled trial. Complementary Med Res 1992;6:66-8.

96. Vyas R, Dikshit N. Effect of meditation on respiratory system, cardiovascular system and lipid profile. Indian J Physiol Pharmacol 2002;46:487-91.

97. Patel C. Reduction of serum cholesterol and blood pressure in hypertensive patients by behaviour modification. J Roy Coll Gen Practitioners 1976; 26:211-5

98. Schmidt T, Wijga A, Von Zur Muhlen A, Brabant $\mathrm{G}$, Wagner T. Changes in cardiovascular risk factors and hormones during a comprehensive residential three month kriya yoga training and vegetarian nutrition. Acta Physiol Scand Suppl 1997; 640:158-62.

99. Mahajan A, Reddy K, Sachdeva U. Lipid profile of coronary risk subjects following yogic lifestyle intervention. Indian Heart J 1999;51:37-40.

100. Jatuporn S, Sangwatanaroj S, Saengsiri A, et al. Short-term effects of an intensive lifestyle modification program on lipid peroxidation and antioxi- dant systems in patients with coronary artery disease. Clin Hemorheol Microcirc 2003;29:429-36.

101. van Montfrans G, Karemaker J, Wieling W, Dunning A. Relaxation therapy and continuous ambulatory blood pressure in mild hypertension: a controlled study. BMJ 1990;300:1368-72.

102. Patel C, Marmot MG, Terry DJ. Controlled trial of biofeedback-aided behavioural methods in reducing mild hypertension. Br Med J (Clin Res Ed) 1981;282:2005-8.

103. Satyanarayana M, Rajeswari KR, Rani NJ, Krishna CS, Rao PV. Effect of Santhi Kriya on certain psychophysiological parameters: a preliminary study. Indian J Physiol Pharmacol 1992;36:88-92.

104. Telles S, Nagarathna R, Nagendra HR, Desiraju T. Physiological changes in sports teachers following 3 months of training in Yoga. Indian J Med Sci 1993; 47:235-8.

105. Raju PS, Prasad KV, Venkata RY, Murthy KJ, Reddy $\mathrm{MV}$. Influence of intensive yoga training on physiological changes in 6 adult women: a case report. J Altern Complementary Med 1997;3:291-5.

106. Bera TK, Rajapurkar MV. Body composition, cardiovascular endurance and anaerobic power of yogic practitioner. Indian J Physiol Pharmacol 1993; 37:225-8.

107. Murugesan R, Govindarajulu N, Bera T. Effect of selected yogic practices on the management of hypertension. Indian J Physiol Pharmacol 2000;44: 207-10.

108. Tran MD, Holly RG, Lashbrook J, Amsterdam EA. Effects of Hatha Yoga practice on the health-related aspects of physical fitness. Prev Cardiol 2001; 4:165-70.

109. Latha Kaliappan K. Yoga, pranayama, thermal biofeedback techniques in the management of stress and high blood pressure. J Indian Psychol 1991;9: 36-46.

110. Schell F, Allolio B, Schonecke O. Physiological and psychological effects of Hatha-Yoga exercise in healthy women. Int J Psychosom 1994;41:46-52.

111. Konar D, Latha R, Bhuvaneswaran JS. Cardiovascular responses to head-down-body-up postural exercise (Sarvangasana). Indian J Physiol Pharmacol 2000;44:392-400.

112. Gopal KS, Bhatnagar OP, Subramanian N, Nishith SD. Effect of yogasanas and pranayamas on blood pressure, pulse rate and some respiratory functions. Indian J Physiol Pharmacol 1973;17:273-6.

113. Raju PS, Madhavi S, Prasad KV, et al. Comparison of effects of yoga and physical exercise in athletes. Indian J Med Res 1994;100:81-6.

114. Bowman A, Clayton R, Murray A, Reed J, Subhan $M$, Ford G. Effects of aerobic exercise training and yoga on the baroreflex in healthy elderly persons. Eur J Clin Invest 1997;27:443-9.

115. Udupa K, Madanmohan, Bhavanani AB, Vijayalakshmi P, Krishnamurthy N. Effect of pranayam 
training on cardiac function in normal young volunteers. Indian J Physiol Pharmacol 2003;47:2733.

116. Anantharaman R, Kabir R. A study of Yoga. J Psychol Res 1984;28:97-101.

117. Mogra A, Singh G. Effect of biofeedback and yogic relaxation exercise on the blood pressure levels of hypertensives: a preliminary study. Aviation Med 1986;30:68-75.

118. Lakshmikanthan C, Alagesan R, Thanikachalam S, et al. Long term effects of yoga on hypertension and/or coronary artery disease. J Assoc Physicians India 1979;27:1055-8.

119. Sundar S, Agrawal S, Singh V, Bhattacharya S, Udupa K, Vaish S. Role of yoga in management of essential hypertension. Acta Cardiol 1984;39: 203-8.

120. Selvamurthy $W$, Sridharan K, Ray U, et al. A new physiological approach to control essential hypertension. Indian J Physiol Pharmacol 1998;42:20513.

121. Patel C. 12-month follow-up of yoga and bio-feedback in the management of hypertension. Lancet 1975;1:62-4.

122. Patel C, Datey KK. Relaxation and biofeedback techniques in the management of hypertension. Angiology 1976;27:106-13.

123. Chaudhary AK, Bhatnagar HN, Bhatnagar LK, Chaudhary K. Comparative study of the effect of drugs and relaxation exercise (yoga shavasan) in hypertension. J Assoc Physicians India 1988;36: 721-3.

124. Stone RA, DeLeo J. Psychotherapeutic control of hypertension. N Engl J Med 1976;294:80-4.

125. Bagga OP, Gandhi A. A comparative study of the effect of Transcendental Meditation (T.M.) and Shavasana practice on cardiovascular system. Indian Heart J 1983;35:39-45.

126. Cusumano JA, Robinson SE. The short-term psychophysiological effects of hatha yoga and progressive relaxation on female Japanese students. Appl Psychol 1992;42:77-90.

127. Ray U, Mukhopadhyaya S, Purkayastha S, et al. Effect of yogic exercises on physical and mental health of young fellowship course trainees. Indian J Physiol Pharmacol 2001;45:37-53.

128. Harinath K, Malhotra AS, Pal K, et al. Effects of Hatha yoga and Omkar meditation on cardiorespiratory performance, psychologic profile, and melatonin secretion. J Altern Complementary Med 2004;10:261-8.

129. Patel C, Marmot M. Can general practitioners use training in relaxation and management of stress to reduce mild hypertension? Br Med J (Clin Res Ed) 1988;296:21-4.

130. Patel C, North WR. Randomised controlled trial of yoga and bio-feedback in management of hypertension. Lancet 1975;2:93-5.
131. Broota A, Varma R, Singh A. Role of relaxation in hypertension. J Indian Acad Appl Psychol 1995;21: 29-36.

132. Dhalla N, Temsah R, Netticadan T. Role of oxidative stress in cardiovascular diseases. J Hypertens 2000;18:655-73.

133. Lee KU. Oxidative stress markers in Korean subjects with insulin resistance syndrome. Diabetes Res Clin Pract 2001;54(Suppl 2):S29-33.

134. Kohler HP. Insulin resistance syndrome: interaction with coagulation and fibrinolysis. Swiss Medical Weekly 2002;132:241-52.

135. Maritim A, Sanders R, Watkins JB 3rd. Diabetes, oxidative stress, and antioxidants: a review. J Biochem Mol Toxicol 2003;17:24-38.

136. Chohan IS, Nayar HS, Thomas P, Geetha NS. Influence of yoga on blood coagulation. Thromb Haemostasis 1984;51:196-7.

137. Bhattacharya S, Pandey U, Verma N. Improvement in oxidative status with yogic breathing in young healthy males. Indian J Physiol Pharmacol 2002;46: 349-54.

138. Sharma H, Sen S, Singh A, Bhardwaj NK, Kochupillai V, Singh N. Sudarshan Kriya practitioners exhibit better antioxidant status and lower blood lactate levels. Biol Psychol 2003;63:281-91.

139. Joshi L, Joshi V, Gokhale L. Effect of short term 'Pranayam' practice on breathing rate and ventilatory functions of lung. Indian J Physiol Pharmacol 1992;36:105-8.

140. Vempati R, Telles S. Baseline occupational stress levels and physiological responses to a two day stress management program. J Indian Psychol 2000;18:33-7.

141. Telles S, Narendran S, Raghuraj P, Nagarathna R, Nagendra H. Comparison of changes in autonomic and respiratory parameters of girls after yoga and games at a community home. Percept Mot Skills 1997;84:251-7.

142. Harte JL, Eifert GH, Smith R. The effects of running and meditation on beta-endorphin, corticotropin-releasing hormone and cortisol in plasma, and on mood. Biol Psychol 1995;40:251-65.

143. Vempati R, Telles S. Yoga-based guided relaxation reduces sympathetic activity judged from baseline levels. Psychol Rep 2002;90:487-94.

144. Bera TK, Gore MM, Oak JP. Recovery from stress in two different postures and in Shavasana-a yogic relaxation posture. Indian J Physiol Pharmacol 1998;42:473-8.

145. Telles S, Nagarathna R, Nagendra HR. Autonomic changes during "OM" meditation. Indian J Physiol Pharmacol 1995;39:418-20.

146. Panjwani U, Gupta HL, Singh SH, Selvamurthy W, Rai UC. Effect of Sahaja yoga practice on stress management in patients of epilepsy. Indian J Physiol Pharmacol 1995;39:111-6.

147. Udupa KN, Singh RH, Dwivedi KN, Pandey HP, 
Rai V. Comparative biochemical studies on meditation. Indian J Med Res 1975;63:1676-9.

148. Nazzaro P, Triggiani R, Ciancio L, Scarano AM, Pirrelli AM. Insulin resistance in essential hypertension: a psychophysiological approach to the "chicken and egg" question. Nutr Metab Cardiovasc Dis 2000;10:275-86.

149. Moan A, Nordby G, Rostrup M, Eide I, Kjeldsen SE. Insulin sensitivity, sympathetic activity, and cardiovascular reactivity in young men. Am J Hypertens 1995;8:268-75.

150. Mezzacappa ES, Kelsey RM, Katkin ES, Sloan RP. Vagal rebound and recovery from psychological stress. Psychosom Med 2001;63:650-7.

151. Khanam AA, Sachdeva U, Guleria R, Deepak KK. Study of pulmonary and autonomic functions of asthma patients after yoga training. Indian J Physiol Pharmacol 1996;40:318-24.

152. Patel C. Yoga and biofeedback in the management of 'stress' in hypertensive patients. Clin Sci Mol Med Suppl 1975;2:171s-4s.

153. Muralidhara DV, Ranganathan KV. Effect of yoga practice on Cardiac Recovery Index. Indian J Physiol Pharmacol 1982;26:279-83.

154. Buchman TG, Stein PK, Goldstein B. Heart rate variability in critical illness and critical care. Curr Opin Crit Care 2002;8:311-5.

155. Pumprla J, Howorka K, Groves D, Chester M, Nolan J. Functional assessment of heart rate variability: physiological basis and practical applications. Int J Cardiol 2002;84:1-14.

156. Miller AW, Sims JJ, Canavan A, Hsu T, Ujhelyi MR. Impaired vagal reflex activity in insulin-resistant rats. J Cardiovasc Pharmacol 1999;33: 698-702.

157. Janakiramaiah N, Gangadhar B, Murthy P, et al. Therapeutic efficacy of Sudarshan Kriya Yoga (SKY) in dysthymic disorder. NIMHANS J 1998; 16:21-8.

158. Carlson LE, Speca M, Patel KD, Goodey E. Mindfulness-based stress reduction in relation to quality of life, mood, symptoms of stress and levels of cortisol, dehydroepiandrosterone sulfate (DHEAS) and melatonin in breast and prostate cancer outpatients. Psychoneuroendocrinology 2004;29:448-74.

159. Sahajpal P, Ralte R. Impact of induced yogic relaxation training (IYRT) on stress-level, self-concept and quality of sleep among minority group individuals. J Indian Psychol 2000;18:66-73.
160. Walia IJ, Mehra P, Grover P, Earnest C, Verma SK, Sanjeev. Health status of nurses and yoga. IV. Experiment and results. Nurs J India 1992;83:27-8.

161. Shannahoff-Khalsa DS, Ray LE, Levine S, Gallen CC, Schwartz BJ, Sidorowich JJ. Randomized controlled trial of yogic meditation techniques for patients with obsessive compulsive disorders. CNS Spectrums: Int J Neuropsychiat Med 1999;4:3446.

162. Berger B, Owen D. Mood alteration with yoga and swimming: aerobic exercise may not be necessary. Percept Mot Skills 1992;75:1331-43.

163. Ernst E, Rand J, Stevinson C. Complementary therapies for depression: an overview. Arch Gen Psychiatry 1998;55:1026-32.

164. Janakiramaiah N, Gangadhar B, Naga Venkatesha Murthy P, Harish M, Subbakrishna D, Vedamurthachar A. Antidepressant efficacy of Sudarshan Kriya Yoga (SKY) in melancholia: a randomized comparison with electroconvulsive therapy (ECT) and imipramine. J Affect Disord 2000;57: 255-9.

165. Jorm A, Christensen H, Griffiths K, Rodgers B. Effectiveness of complementary and self-help treatments for depression. Med J Aust 2002;176 Suppl: S84-96.

166. Platania-Solazzo A, Field T, Blank J, et al. Relaxation therapy reduces anxiety in child and adolescent psychiatric patients. Acta Paedopsychiatrica 1992;55:115-20.

167. Netz Y, Lidor R. Mood alterations in mindful versus aerobic exercise modes. J Psychol Res 2003;137: 405-19.

168. Bhushan S, Sinha P. Yoganidra and management of anxiety and hostility. J Indian Psychol 2001;19: 44-9.

169. Allen KS, Steinkohl RP. Yoga in a geriatric mental clinic. Act Adapt Aging 1987;9:61-8.

170. Joseph CD. Psychological supportive therapy for cancer patients. Indian J Cancer 1983;20:268-70.

171. Cohen L, Warneke C, Fouladi RT, Rodriguez MA, Chaoul-Reich A. Psychological adjustment and sleep quality in a randomized trial of the effects of a Tibetan yoga intervention in patients with lymphoma. Cancer 2004;100:2253-60.

172. Vickers A, Goyal N, Harland R, Rees R. Do certain countries produce only positive results? A systematic review of controlled trials. Control Clin Trials 1998;19:159-66. 